\title{
Prácticas de justicia conciliatoria y sus dimensiones sociales. Chile, $1830-1836^{1}$
}

\author{
por \\ Verónica Undurraga Schüler \\ Pontificia Universidad Católica de Chile \\ vundurra@uc.cl
}

Este trabajo analiza las prácticas de la justicia conciliatoria y el perfil social de sus usuarios en las villas y ciudades de Chile central, luego de la implementación de la conciliación como trámite previo a la presentación de demanda judicial ante los tribunales ordinarios entre 1824 y 1836. A partir de 299 juicios de conciliación se propone que la justicia conciliatoria fue un mecanismo de resolución de los conflictos usado preferentemente por los sectores alto y medio-alto ilustrado de las comunidades locales, que eran justamente quienes permitían su accionar ejerciendo distintas funciones administrativas. La activa participación de la comunidad -más bien de dicho sector de la comunidad local-fue determinante en la validación de esta «nueva» instancia de resolución de los conflictos, constatando el carácter activo de la sociedad en la legitimación de la legalidad y la institucionalidad estatal.

Palabras Clave: justicia conciliatoria; resolución de conflictos; Chile central; siglo XIX.

La construcción del Estado integró diversos procesos y actores tanto modernos como tradicionales -que pervivieron y se resignificaron con el paso del tiempo-, y que fueron tanto exitosos como fallidos o con corta $v^{2} \mathrm{da}^{2}$. Siguiendo a António Manuel Hespanha, el estudio de los procesos y actores de aparente menor relevancia permite comprender las dificultades del proceso de

\footnotetext{
${ }^{1}$ Este trabajo es producto del proyecto CONICYT, FONDECYT Regular N ${ }^{\circ} 1130211$ "Formas de conciliación y mecanismos informales de resolución de conflictos en Chile, 17501850", del cual soy Investigadora Responsable. Agradezco el acucioso trabajo realizado por Valentina Bravo y Jeniffer Cerón en la transcripción de documentos, así como las sugerencias de los evaluadores que han enriquecido este artículo.

2 Yangilevich, 2010: 130. Fradkin, 2009b: 143-164.
} 
construcción del Estado y conocer, de manera privilegiada, las instituciones y las formas de poder $^{3}$. Esto ocurre con el desarrollo de la justicia conciliatoria en Chile, la que si bien estuvo presente en la normativa desde el proyecto de constitución de 1811, no se hizo efectiva sino hasta la promulgación de la Constitución de 1823 y del Reglamento de Administración de Justicia de 1824. Desde este año, la conciliación como instancia preceptiva para dirimir los conflictos relativos a cuestiones civiles y por injurias, se mantuvo vigente hasta 1836 aunque subsistiendo en la justicia comercial hasta el año 1855.

La conciliación, como instancia previa al juicio, se inscribe en un momento de transición en el orden jurídico hispánico en el que, según Carlos Garriga, se habría producido el paso desde «un orden jurídico tradicional (que reconoce la tradición como derecho), a un orden jurídico legal (porque identifica el derecho como la ley, como disposición de la autoridad constituida)» ${ }^{4}$. Ahora bien, como ha destacado Federica Morelli en relación a la Constitución gaditana, «a pesar de la introducción de principios como la separación de poderes, la supremacía del legislativo y la subordinación del juez a la normativa procedente de aquél, la justicia no se cambió» ${ }^{5}$. A lo largo del siglo XIX en el mundo hispanoamericano, se planteó la convivencia de la novedad con la tradición y la justicia «podría ser letrada y ajena a las corporaciones municipales, o lega, electiva, y, por tanto, vinculada a éstas» ${ }^{6}$. Ello explica, en primer lugar, la imprecisión en la conceptualización de la conciliación en el periodo estudiado pues, como ha planteado Antonio Dougnac, si bien ella «no sería un acto de jurisdicción sino de intervención amistosa, ni un ejercicio de autoridad sino de mediación en orden a avenir a las partes [...] por otra parte, los jueces conciliadores han de dictar una suerte de sentencia de conciliación, que implica una actividad jurisdiccional» ${ }^{7}$. En segundo lugar, la coexistencia de elementos de novedad y de tradición en la justicia conciliatoria también aclara, para el caso chileno, las críticas realizadas a las actuaciones de los jueces conciliadores y a la instancia de la conciliación en general. Estaban planteadas desde la preocupación de los agentes del Estado por la profesionalización de la judicatura, la que implicaba pasar de una «justicia de jueces» a una «justicia de leyes», como ha planteado Marta Lorente ${ }^{8}$.

3 Hespanha, 1989.

${ }^{4}$ Garriga, 2010: 62. Clavero, Portillo y Lorente, 2004. Garriga y Lorente, 2007.

5 Morelli, 2008: 45.

${ }^{6}$ Ibidem: 48.

7 Dougnac, 1996: 167-168. El debate de las Cortes de 1821 concluyó que «el acto de conciliación no podía ser considerado como un juicio, lo que permitió la participación de aforados», como los militares. Sala i Vila, 2012: 434.

${ }^{8}$ Lorente, 2007. 
Este trabajo busca conocer y analizar un problema aún no estudiado en profundidad por la historiografía chilena, que sólo se ha aproximado al tema desde una perspectiva normativa: el funcionamiento y los usos de la justicia conciliatoria en las villas y ciudades de Chile, luego de la implementación de la conciliación como trámite previo a la presentación de demanda judicial ante los tribunales ordinarios ${ }^{9}$. Ahora bien, la relevancia de esta aproximación no sólo se relaciona con la novedad del objeto de estudio sino también con que ésta permite iluminar una serie de problemas históricos y epistemológicos relacionados. En las villas y ciudades chilenas la justicia conciliatoria era impartida por alcaldes ordinarios, quienes desde su posición como vecinos reconocidos debían dirimir los conflictos de los integrantes de la comunidad. En consecuencia, este trabajo contribuye a la discusión sobre las actuaciones de los jueces legos en Chile, quienes integraban mayoritariamente el personal judicial durante el siglo XIX. Al mismo tiempo, introduce en el análisis el papel central desempeñado por los escribanos quienes, como mediadores entre la justicia conciliatoria y la comunidad, contribuyeron de manera relevante al funcionamiento y legitimación de esta instancia.

Nuestra investigación no busca resolver el debate en torno al carácter liberal o tradicional de la justicia conciliatoria -en otras palabras, a si ésta reprodujo prácticas tradicionales o nació de innovaciones planteadas en el debate de las Cortes de Cádiz- ${ }^{10}$, así como tampoco supone que la justicia conciliatoria fue una simple «apropiación» de la técnica del arbitraje por el Estado, que las comunidades venían desarrollando durante los siglos coloniales ${ }^{11}$. Esta última concepción supone la existencia de una dicotomía entre Estado y sociedad, sólo interrumpida por las acciones del primero sobre la segunda, expresadas a través del disciplinamiento y la imposición de la legalidad y la autoridad ${ }^{12}$. Por el contrario, la idea que anima este trabajo se inserta en la propuesta de Galante, Irurozqui y Argeri que busca replantear las relaciones entre ley, Estado y sociedad, atendiendo a «la capacidad de la sociedad para intervenir en la conformación de la legalidad. Ello afecta directamente al reconocimiento

${ }^{9}$ La principal contribución a la materia, que además contiene una escueta referencia a las actuaciones como conciliadores de dos Ministros de la Corte Suprema, es la de Dougnac, 1996: 111-168. Valenzuela, 1981: 81-84.

${ }^{10}$ Lorente, 2014: 279-298. Ossa, 2014: 255-278.

${ }^{11}$ Esta última perspectiva supone que los arreglos extrajudiciales se desarrollaban al margen del sistema de justicia, lo que ha sido rebatido por la historiografía. Los perdones de parte y los acuerdos particulares constituían una estrategia complementaria, no opuesta, a la vía judicial. Undurraga, 2015: 41-61. Agüero, 2008: 145-166. Di Gresia, 2010: 181-184.

12 Una discusión sobre los diversos modelos de disciplinamiento y control social en Undurraga y Gaune, 2014: 21-45. 
del Estado y de su poder, para lo que no se atiende exclusivamente a su capacidad para imponer su autoridad y control sobre la sociedad, sino también a la capacidad de ésta para participar en la legitimación, la construcción del significado y la puesta en práctica de dicho poder» ${ }^{13}$.

La historiografía chilena ha considerado que el periodo en el que se enmarca este trabajo fue relevante en la consolidación del así llamado «Estado oligárquico liberal», que se extendió entre 1810 y 1920 y que fue legitimado a través de la Constitución de $1833^{14}$. Entendemos esta organización institucional como producto y, a la vez, como condicionante de las tensiones, disputas y equilibrios de las elites chilenas. Siguiendo a Irurozqui y Galante, nos aproximamos al Estado desde «su complejidad socio-institucional» comprendiéndolo como «un conjunto de entramados institucionales y organizativos formales e informales que se construyen en continuos procesos de negociación, disputa y acuerdos entre grupos específicos de actores $\rangle^{15}$.

Partiendo de la base de la permanente interacción entre la construcción estatal y los sujetos que, situados tanto dentro como fuera de las instituciones, intervinieron en este proceso ${ }^{16}$, el presente trabajo se aproxima a las actuaciones de los tribunales de conciliación buscando conocer quiénes fueron los usuarios de la justicia conciliatoria y si el modelo de arbitraje propuesto por la administración de justicia constituyó efectivamente un espacio de negociación y de resolución de los conflictos en Chile central durante el siglo XIX. Ello se ha abordado a través del estudio de dos comunidades locales, Quillota y Rengo, para las cuales fue posible reconstruir 299 juicios de conciliación desarrollados entre los años 1830 y 1836. La información contenida en ellos fue sometida a un análisis de tipo cuantitativo y cualitativo, permitiendo postular que la justicia conciliatoria fue un mecanismo de resolución de los conflictos usado preferentemente por los sectores alto y medio-alto ilustrado de las comunidades locales, que eran justamente quienes intervenían en su funcionamiento como jueces de conciliación, jueces compromisarios, árbitros, arbitradores, amigables componedores, peritos y escribanos. La activa participación de la comunidad -más bien de dicho sector de la comunidad local- fue determinante en la validación de esta «nueva» instancia de resolución de los conflictos, permitiendo constatar el carácter activo de la sociedad en la legitimación de la legalidad y la institucionalidad estatal.

${ }^{13}$ Galante, Irurozqui y Argeri, 2011.

${ }^{14}$ Salazar y Pinto, 1999.

15 Irurozqui y Galante, 2011: 11-12.

16 Sobre este problema ver la completa discusión bibliográfica propuesta en: Galante, Irurozqui y Argeri, 2011: 9-27. 
Las localidades escogidas cuentan con los registros más completos para reconstruir las prácticas relativas a la justicia conciliatoria $\mathrm{y}$, a la vez, son comunidades representativas de Chile central en el periodo en que esta rigió. Chile era un país predominantemente rural en el que ciudades como Santiago, su capital, Valparaíso y Concepción constituían excepciones. En ese contexto, asentamientos como Quillota o Rengo expresaban las formas de vida, las dinámicas sociales y los mecanismos de supervivencia de la mayoría de las villas de Chile central ${ }^{17}$. La ciudad de Quillota, de mayor antigüedad, relevancia económica e importancia estratégica que la villa de Rengo, estaba emplazada a 88 kilómetros al noroeste de Santiago y a 39 kilómetros al noreste de Valparaíso. Fue erigida como parroquia en 1585 para luego ser el centro del antiguo corregimiento de Quillota. En 1717 se fundó oficialmente su villa principal, llamada San Martín de la Concha, luego rebautizada como «Quillota». En 1776 la Ordenanza de Intendentes convirtió el corregimiento de Quillota en delegación o partido -formando parte de la Intendencia de Santiago- y en 1826 se transformó en departamento dependiente de la recién creada provincia de Aconcagua ${ }^{18}$. Su ubicación estratégica entre Valparaíso y Santiago contribuyó a su desarrollo y dado que su primordial actividad económica era la agricultura, Quillota fue el principal centro de abastecimiento de productos agrícolas a Valparaíso.

La villa de Rengo, ubicada a 113 kilómetros al sur de Santiago de Chile, fue fundada como villa en 1692 con el nombre de «Lugar de Río Claro o clarillo», dando cuenta de la relevancia de este río en el desarrollo de su población ${ }^{19}$. Su principal actividad económica, al igual que la de la zona en la que estaba emplazada, era la agricultura y en particular la vitivinicultura. Durante el periodo estudiado, Rengo formaba parte del partido de Caupolicán, el que a su vez pertenecía a la provincia de Colchagua ${ }^{20}$. Dentro de esta provincia, Rengo era un emplazamiento de menor importancia. A mediados del siglo XIX la población total de Colchagua ascendía a 192.704 habitantes y el partido de Caupolicán contaba con 9 subdelegaciones y 32 inspectorías ${ }^{21}$.

17 Bauer, 1994. Salinas, 2005: 11-47.

18 Keller, 1960: 122.

19 Días Blanco, 2011: 97-130. Valenzuela Solís de Oviedo, 1997.

20 Actas de Conciliación, 1835, Archivo Nacional de la Administración, Chile (en adelante ANA) Fondo Notarios de Rengo (en adelante FNR), vol. 20, fj. 169.

${ }^{21}$ Pérez Rosales, 2010: 121. 
Mapa de la República de Chile (1855) en el Que destacamos la CiUdad de Quillota y la villa de Rengo

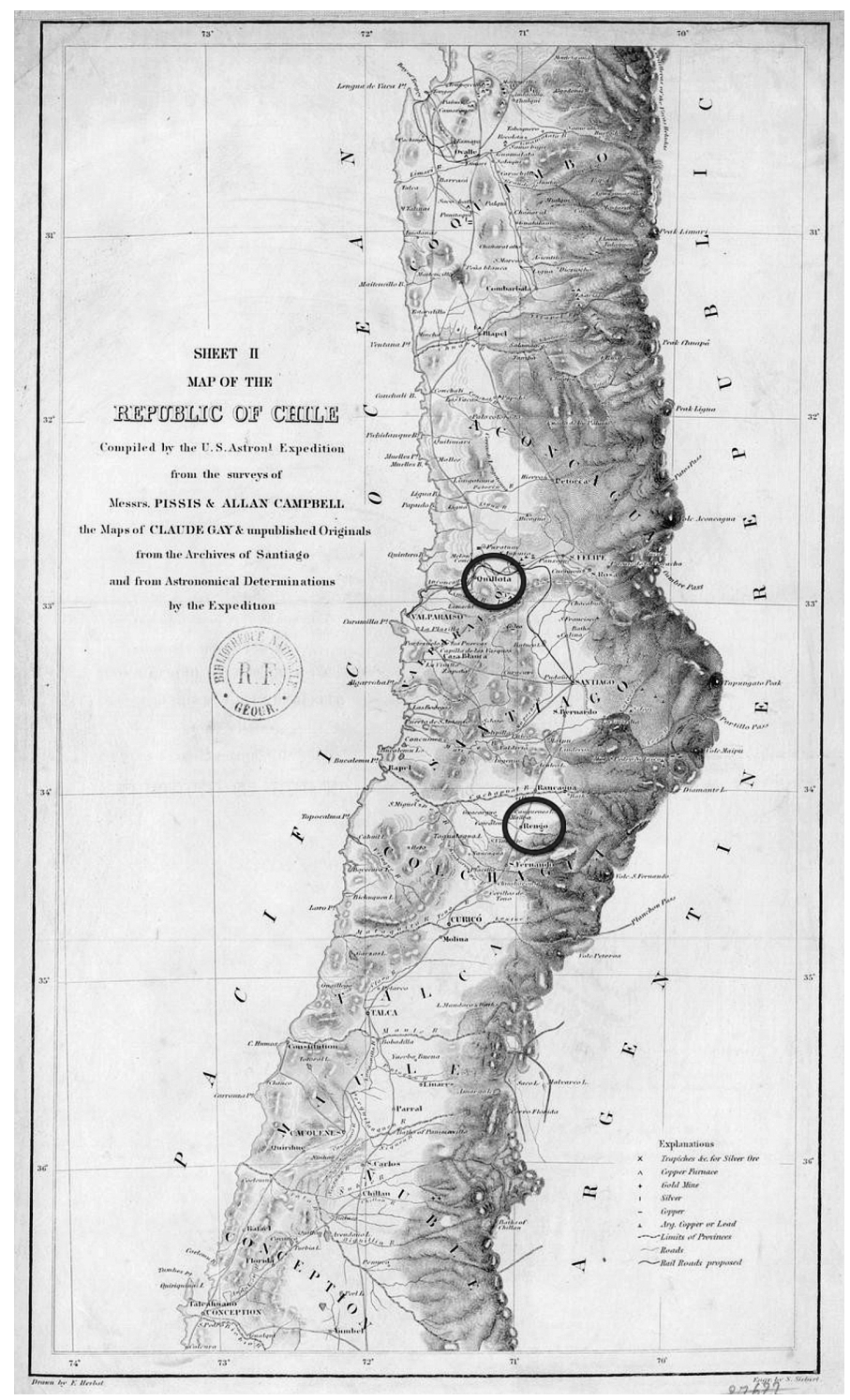

Fuente: Sheet II Map of the republic of Chile, compiled by the U. S. Astron Expedition from the surveys of Messrs. Pissis \& Allan Campbell the Maps of Claude Gay \& unpublished originals from the Archives of Santiago and from Astronomical Determinations by the Expedition drawn by F. Herbst. [1855]. En: gallica.bnf.fr / Bibliothèque Nationale de France. 
Historiografía y Reglamentación de la Justicia Conciliatoria en Chile, $1811-1836$

La historiografía argentina ha estudiado profusamente la justicia de paz. Sus trabajos, al relevar los elementos de continuidad y de novedad de la institución, coinciden en señalar su consolidación y validación social en las zonas rurales $^{22}$. Raúl Fradkin ha destacado la importancia de los atributos personales tanto de los jueces de paz como de sus subalternos en la consolidación de la justicia de paz en la provincia de Buenos Aires desde 182123. A partir del análisis de las tradiciones que reglamentaron la justicia de paz y sus prácticas en Mendoza a partir de 1872, Inés Elena Sanjurjo concluye que estos juzgados resolvieron los conflictos cotidianos particularmente de los sectores medios de la sociedad ${ }^{24}$. Melina Yangilevich ha planteado que las prácticas de los jueces de paz y sus auxiliares fueron determinantes en la construcción del Estado, pues tornaron «efectiva una jurisdicción en territorios alejados de las autoridades centrales» ${ }^{25}$. Los juzgados de paz, en particular durante el gobierno de Rosas, habrían sido piezas centrales en la imposición de un orden y en el control sobre la campaña bonaerense. Asimismo, estos habrían constituido «instancias de aprendizaje» y de socialización de la cultura jurídica $^{26}$, en particular de la «cultura judicial lega», según ha sostenido Leandro A. Di Gresia ${ }^{27}$. Asimismo, el interesante estudio de Nuria Sala i Vila sobre la justicia conciliatoria en el Perú destaca la influencia de la Constitución de 1812 en la configuración de la conciliación como trámite previo y necesario para solucionar los conflictos ante la justicia letrada ${ }^{28}$. Con ello, la autora se aproxima al complejo problema de la transición, coexistencia y tensiones entre la cultura jurídica ilustrada y la liberal, en el ámbito municipal durante las primeras décadas del siglo XIX, postulando que los ayuntamientos actuaron como defensores de los principios liberales ${ }^{29}$.

En el caso chileno, la preocupación por los costos y la lentitud de los procesos judiciales llevó a incluir el trámite de la conciliación en diversas consti$8-10$.

${ }^{22}$ Gelman, 2000: 7-32. Garavaglia, 1999: 89-121. Yangilevich, 2011: 84. Sanjurjo, 2010:

${ }^{23}$ Fradkin, 2009b: 143-164.

24 Sanjurjo, 2010: 9.

${ }^{25}$ Yangilevich, 2011: 75.

26 Ibidem: 91.

${ }^{27}$ Hespanha, 2002. Di Gresia, 2010: 156-191. Fradkin, 2009a.

28 Sala i Vila, 2012: 423-450.

${ }^{29}$ Ibidem: 424. Sobre las culturas jurídicas y el proceso de construcción del Estado republicano, véase Peralta, 2010. 
tuciones y reglamentos de justicia desde los inicios de la vida republicana. La introducción de la conciliación como instancia preceptiva al desarrollo de los juicios civiles y por injurias comenzó con la incorporación de un Tribunal de Paz en el proyecto constitucional de $1811^{30}$. Luego, este trámite fue acogido en las constituciones políticas de 1822 , de 1828 y en el título primero del proyecto de Reglamento de Administración de Justicia de 1823 de Mariano Egaña. La Constitución de 1823 introducía la conciliación como instancia preliminar de «toda demanda civil i las criminales que admitan transacción sin perjuicio de la causa pública» y establecía que «ninguno puede presentarse a los tribunales ordinarios con demanda judicial, sin haber ocurrido a los de conciliación ${ }^{31}$. Si las partes no aceptaban los términos de la conciliación, podían presentar su queja ante los tribunales ordinarios, previa recepción de un boletín o certificado que acreditaba el paso por dicho trámite. El texto establecía que en Santiago los jueces de conciliación debían ser los Ministros de la Suprema Corte de Justicia, en tanto que los alcaldes municipales asumirían dicha función en las provincias en que existieran jueces de letras ${ }^{32}$. En las provincias en que no hubiera jueces de letras, los regidores actuarían como jueces de conciliación y los alcaldes conocerían en primera instancia. Por último, los prefectos y otros regidores de la Municipalidad conciliarían los asuntos de menor cuantía.

La división territorial de la administración de justicia en Chile durante el siglo XIX se estructuró según el Reglamento de Ley de 1824, el que se apoyaba en la Constitución de 1823 que a su vez reproducía la subdivisión colonial. Siguiendo a Pauline Bilot, «la justicia ordinaria estaba a cargo de los inspectores en los distritos (ex jueces diputados), de los subdelegados en los partidos o subdelegaciones, de los jueces de letras en la cabecera del departamento» ${ }^{33}$. La Corte de Apelaciones debía conocer en segunda instancia las causas civiles y criminales que se le remitían en apelación por los jueces de primera instancia, así como las vejaciones, dilaciones y perjuicios causados en la secuela de los juicios de primera instancia, entre otras materias ${ }^{34}$. La primera magistratura judicial era la Suprema Corte de Justicia, integrada por cuatro ministros, un presidente y el procurador nacional, quienes debían haber ejercido como abogados por más de diez años ${ }^{35}$.

${ }^{30}$ Dougnac, 1996: 114-119.

31 Constitución de 1823, artículo 168 en Anguita, 1912, tomo I: 137.

32 Constitución de 1823, artículos 174 y 175 en Idem.

33 Bilot, 2013: 9.

${ }^{34}$ Reglamento de Administración de Justicia de 1824, artículos 54-76 en Anguita, 1912, tomo I: 155-156.

${ }^{35}$ Constitución de 1823, artículos 143-151 en Ibidem: 135-136. 
Durante el periodo en que actuaron los jueces de conciliación en materias civiles y de injurias, existían siete Juzgados de Letras provinciales, que eran Coquimbo, San Felipe, Valparaíso, San Fernando, Talca, Valdivia y Ancud ${ }^{36}$. A ellos habría que agregar los jueces letrados de Santiago y Concepción, que asesoraban al intendente desde la reforma de las Intendencias en 1786. Los jueces de letras formaban la primera instancia de la justicia ordinaria, en tanto que la justicia ordinaria de menor cuantía la integraban los subdelegados y los inspectores ${ }^{37}$. Según estimaciones de Bilot, durante el siglo XIX en Chile, al menos el $90 \%$ del personal judicial estaba conformado por jueces legos -como inspectores, subdelegados y alcaldes-, quienes no tenían formación en derecho ni eran remunerados por su trabajo ${ }^{38}$. Ante estos funcionarios el Estado chileno asumió una actitud pragmática: como existían limitaciones materiales y humanas para la implantación de una justicia totalmente letrada, se buscó fiscalizar más estrechamente sus actuaciones, junto con contribuir a su formación. Por último, el «apoyarse en las figuras tradicionales de poder [como los jueces legos] respondía también a una estrategia del Estado para construir su legitimidad a costos abaratados y controlar el territorio y sus habitantes ${ }^{39}$.

El Reglamento de Administración de Justicia de 1824 -que representó la mayor reorganización de la administración judicial después de la Independencia- mantuvo los criterios establecidos por la Constitución de 1823 en la regulación de la conciliación, aunque al poco tiempo de ser promulgado se le sumaron algunas disposiciones ${ }^{40}$. Este refrendaba la conciliación como instancia previa a los juicios civiles y por injurias ante los tribunales ordinarios,

${ }^{36}$ El punto de inflexión en la creación de juzgados de letras se produjo en Chile entre los años 1850 y 1860. Bilot, 2013: 12 .

37 Bilot y Whipple, 2014: 481. Los inspectores tenían jurisdicción sobre una comunidad conformada por diez casas habitadas, en tanto que los subdelegados la ejercían sobre cien distritos, lo que equivalía a mil casas. Bilot, 2013: 9 y 18 .

38 «Eran vecinos que accedían a un cargo concejil», es decir asimilado a un servicio obligatorio y gratuito, que entregaban a sus conciudadanos y a la Patria. Una ley de 1838 explicitó que éstos se reclutaban por un periodo de dos años entre los hombres mayores de 25 años, alfabetizados, ciudadanos electores, y destacados por su «notoria reputación de probidad». Bilot, 2013: 10. Sobre jueces legos y su relación con la justicia letrada véase el dossier coordinado por Víctor Brangier en el que colaboran Darío Barriera, Pauline Bilot, Agustín Casagrande, María José Correa, Leandro A. Di Gresia y Carolina González. Brangier, 2012. Barreneche, 2007: 181-202.

39 Bilot y Whipple, 2014: 490.

${ }^{40}$ Los artículos de este Reglamento $-\mathrm{n}^{\circ} 7$ a $\mathrm{n}^{\circ} 23-$ se encuentran en el Título II denominado Juicios de conciliación en Anguita, 1912, tomo I: 151-153. Las disposiciones relativas a la conciliación que se agregaron con posterioridad a dicho reglamento se encuentran en Anguita, 1912, tomo I: 162-163. Sobre los hermanos Egaña véase Castillo, 2009; 2001: 25-40 y Brahm, 2007. 
incluyendo a aquellos que involucraban eclesiásticos y militares. Asimismo, establecía que a la conciliación le competía proceder en causas de divorcio. La Corte de Apelaciones debía conocer las vejaciones y dilaciones causadas por los jueces conciliadores, exceptuando a los Ministros de la Suprema Corte.

La obligatoriedad de pasar por la instancia de la conciliación se extendió durante doce años, siendo eliminada en 1836, luego de un largo debate. Durante dicho periodo se levantaron voces que se oponían a esta instancia, dentro de las cuales destacó la del jurista venezolano Andrés Bello, a quien el gobierno había acudido para analizar el Proyecto de Reglamento de Administración de Justicia de 1831, que incluía la conciliación ${ }^{41}$. Las principales críticas de Bello apuntaban a la ineficacia de la instancia de la conciliación, así como al carácter de la decisión que tomaba el conciliador la que era asumida subjetivamente según el criterio del juez conciliador ${ }^{42}$. Bello objetaba, asimismo, que esta instancia se prestaba a abusos como la dilación en la actuación de la justicia en los conflictos interpersonales, achacada, supuestamente, a la facilidad para recusar a los conciliadores. Pese a estas críticas y a la abolición de la conciliación en materias civiles y de injurias, ésta se mantuvo en la justicia comercial hasta el año 1855. Ningún pleito de mayor cuantía se podía establecer ante el Consulado sin haber pasado previamente por este trámite.

LAS PRÁCTICAS DE LA JUSTICIA CONCILIATORIA EN DOS LOCALIDADES DE CHILE CENTRAL: Quillota y ReNGO ENTRE 1830 y 1836

El análisis de las actas de conciliación registradas en la ciudad de Quillota y en la villa de Rengo permite conocer las prácticas de la justicia conciliatoria desde seis u ocho años y hasta doce años después de promulgado el Reglamento de Administración de Justicia de 1824, respectivamente. En este marco temporal es posible observar, como evidencia el gráfico $\mathrm{n}^{\circ} 1$, que los recursos a los juicios de conciliación en la zona de Quillota mostraron un leve descenso durante los primeros tres años, para luego -desde 1833- ir aumentando hasta alcanzar una importante representación en 1835. Este aumento lo explicaban los conflictos por propiedad de la tierra, que no habían sido relevantes entre 1830 y 1833, pero que comenzando a acrecentarse en 1834, alcanzaron su mayor representación en el año 1835. Los conflictos por derechos heredita-

${ }^{41}$ Jaksic, 2010; 2013. Ossandón y Ruiz, 2013.

42 Algunos hombres públicos de tendencia liberal, como Diego Barros Arana y Domingo Santa María, también se opusieron a la conciliación pues veían en ella un marcado sesgo paternalista. Dougnac, 1996: 146-151. 
GRÁFICO N ${ }^{\circ} 1$

Distribución de juicios de conciliación por año. Quillota.

1830-1836.

Total de ciento cuarenta conciliaciones.

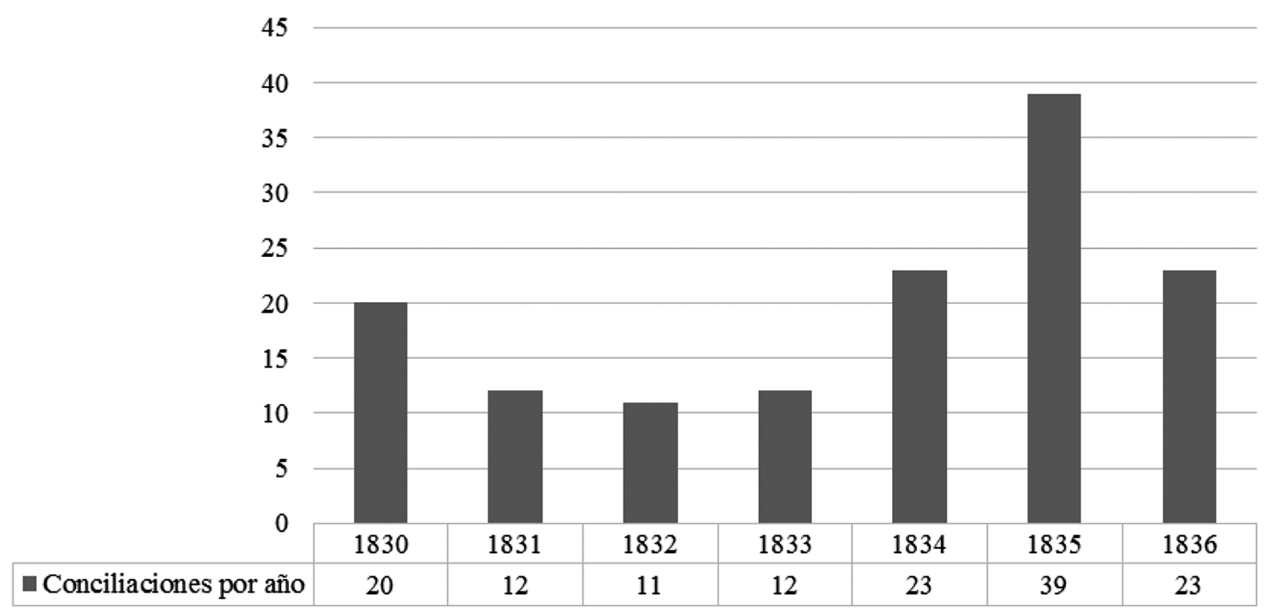

Fuente: Archivo Histórico Nacional, Fondo Judicial de Quillota, leg.12, 1834-1836.

Archivo Nacional de la Administración, Fondo Notarios de Quillota, vol. 51, 1830-1836.

rios y por cobro de pesos mantuvieron una representación importante pero estable a lo largo de todo el periodo. Por otra parte, como muestra el gráfico $\mathrm{n}^{\circ} 2$, los trámites de conciliación en la villa de Rengo, entre 1832 y 1836 , evidencian un alza inicial en el año 1833 para luego estabilizarse en cerca de 29 conciliaciones al año. La curva de Rengo aparece, de este modo, mucho más estable que la de Quillota.

Los tipos de conflictos que se presentaron a juicio de conciliación eran similares en los dos lugares analizados, predominando los problemas de índole económica y de propiedad. Los más recurrentes fueron los que involucraron desavenencias relacionadas con la propiedad y los límites de las tierras, los problemas de herencia y los cobros de pesos. Luego figuraban los interpersonales derivados en injurias. Si bien el tipo de conflictos acogidos al trámite de conciliación era similar en Quillota y en Rengo, la diferencia se planteaba en la distribución numérica de los mismos. En Quillota, si se considera la totalidad de los juicios y ya no su representación en el tiempo, es posible observar una distribución equitativa de los conflictos por tierras, herencia y cobro de pesos, alcanzando una representación prácticamente idéntica, como 
GRÁFICO N ${ }^{\circ} 2$

Distribución de juicios de conciliación por año. Rengo.

1832-1836.

Total de ciento cincuenta y nueve conciliaciones.

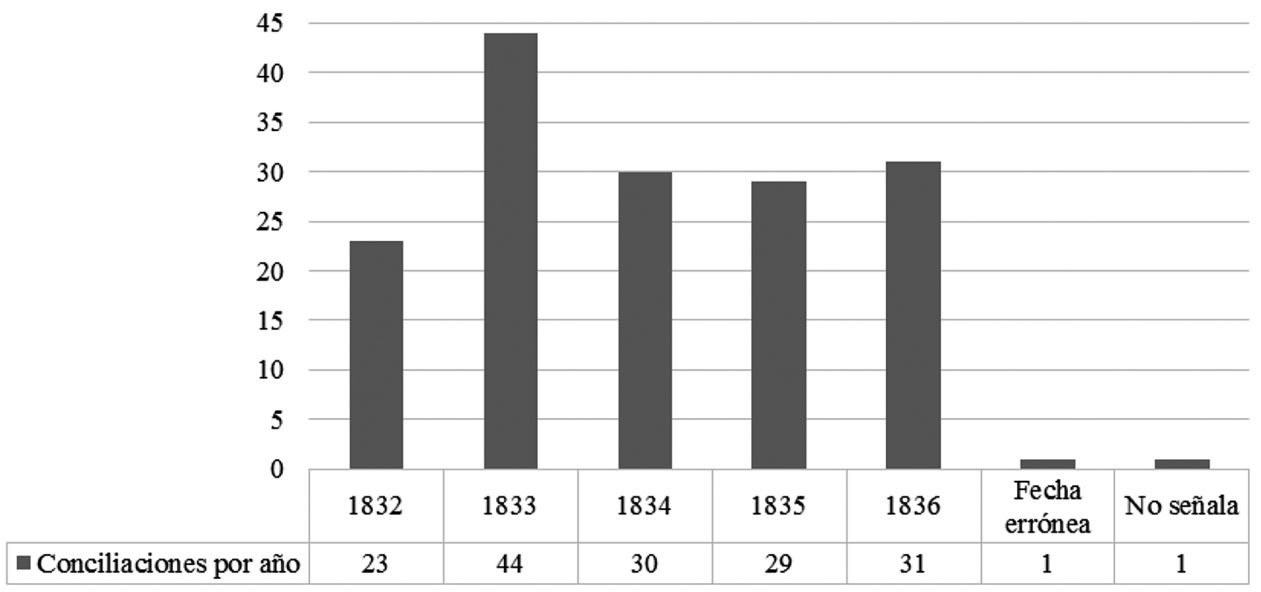

Fuente: Archivo Nacional de la Administración, Fondo Notarios de Rengo vol. 20, 1832-1836.

se observa en el gráfico $\mathrm{n}^{\circ} 3$. Por el contrario, en Rengo, los conflictos por tierras representaban el número más significativo, sumando 47 juicios de conciliación de un total de 159 , como se representa en el gráfico ${ }^{\circ} 4$. Luego venían los juicios por cobro de pesos, con un total de $35 \mathrm{y}$, en tercer lugar, los juicios relacionados con los conflictos por herencia, que alcanzaban un número de 22. Si bien las injurias figuraban en cuarto lugar de importancia numérica en ambos lugares -representando el 9\% de los conflictos registrados-, en Quillota alcanzaban la misma representación de los conflictos por deudas, en tanto que en Rengo tenían mayor representación que el resto de los conflictos registrados en las actas de conciliación. A su vez, en el caso de Quillota, la categoría «otros»-que alcanza el 9\% de la muestra- incluye conflictos tan diversos como robo, relevación de fianza, división de callejón, restitución de dote y violación, entre otros. Sin embargo, en el caso de la villa de Rengo, esta categoría - que alcanza al $6 \%$ de la muestra- contiene juicios de conciliación por deslinde de camino, cobro de arriendo, deuda por servicios prestados, remate de bienes, incumplimiento de compromiso y pago de costas, entre otros. 


\section{GRÁFICO N $\mathrm{N}^{\circ} 3$}

\section{Tipos de confictos presentados a juicio de conciliación.}

Quillota. 1830-1836.

Total de ciento cuarenta conciliaciones.

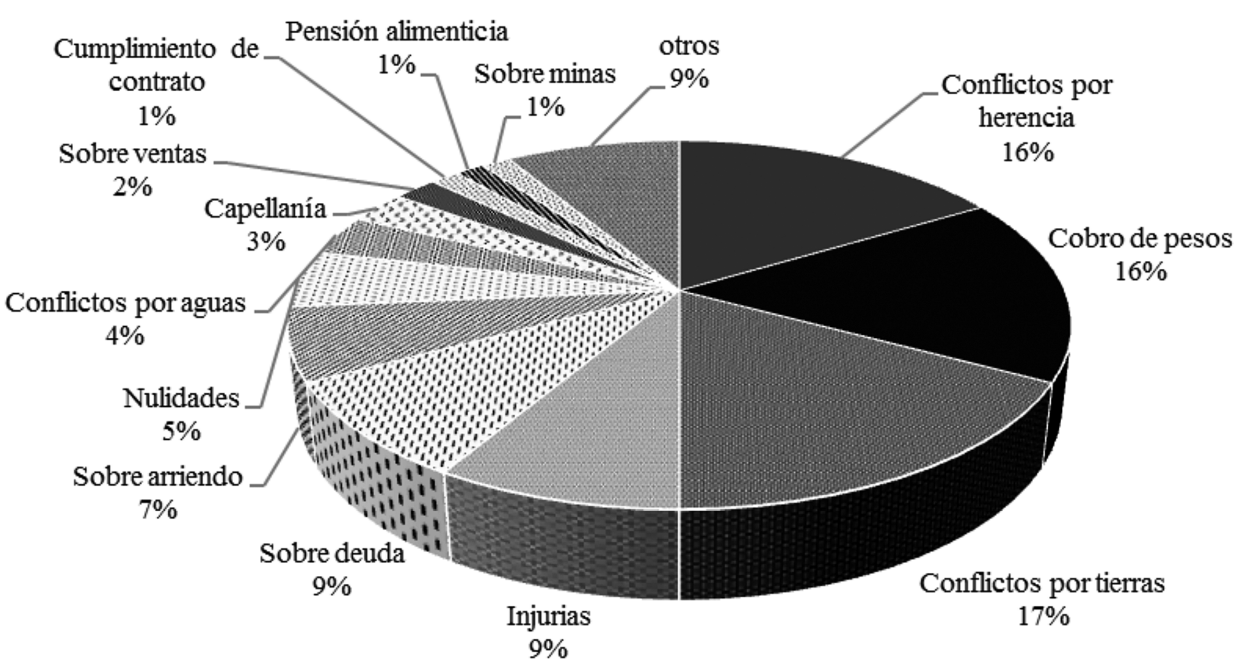

Fuente: Archivo Histórico Nacional, Fondo Judicial de Quillota, leg.12, 1834-1836.

Archivo Nacional de la Administración, Fondo Notarios de Quillota, vol. 51, 1830-1836.

Al comparar las actas de conciliación de Quillota y Rengo es posible constatar una serie de diferencias. Las actas que registraban los juicios de conciliación celebrados en Quillota evidenciaban una clara estructura, detalle y el seguimiento de todas las instancias prescritas en el Reglamento de Administración de Justicia de 1824. Por su parte, las actas de la villa de Rengo eran documentos más escuetos en los que se omitían ciertos nombres y faltaban algunas referencias relevantes. La principal omisión de las actas de conciliación de Rengo era que en su gran mayoría no consignaban el nombre del juez conciliador, el que en ocasiones era mencionado como «juez de paz» ${ }^{43}$. Su participación se designaba en las actas indicando sus acciones, como «mandó el señor Juez», «declaró el Señor Juez» o «no habiendo podido conseguir el Señor Juez se aviniesen ${ }^{44}$. Asimismo, las actas de conciliación de la villa de Rengo indicaban que el juez de conciliación estaba presente en el momento

\footnotetext{
${ }^{43}$ Actas de Conciliación, 1833, ANA, FNR, vol. 20, fjs. 50 y $50 \mathrm{v}$.

${ }^{44}$ Ibidem, 1832, ANA, FNR, vol. 20, fjs. 8, 10, 11v.
} 


\section{GRÁFICO N ${ }^{\circ} 4$}

Tipos de conflictos presentados a juicios de conciliación.

Rengo. 1832-1836.

Total de ciento cincuenta y nueve concilaiciones.

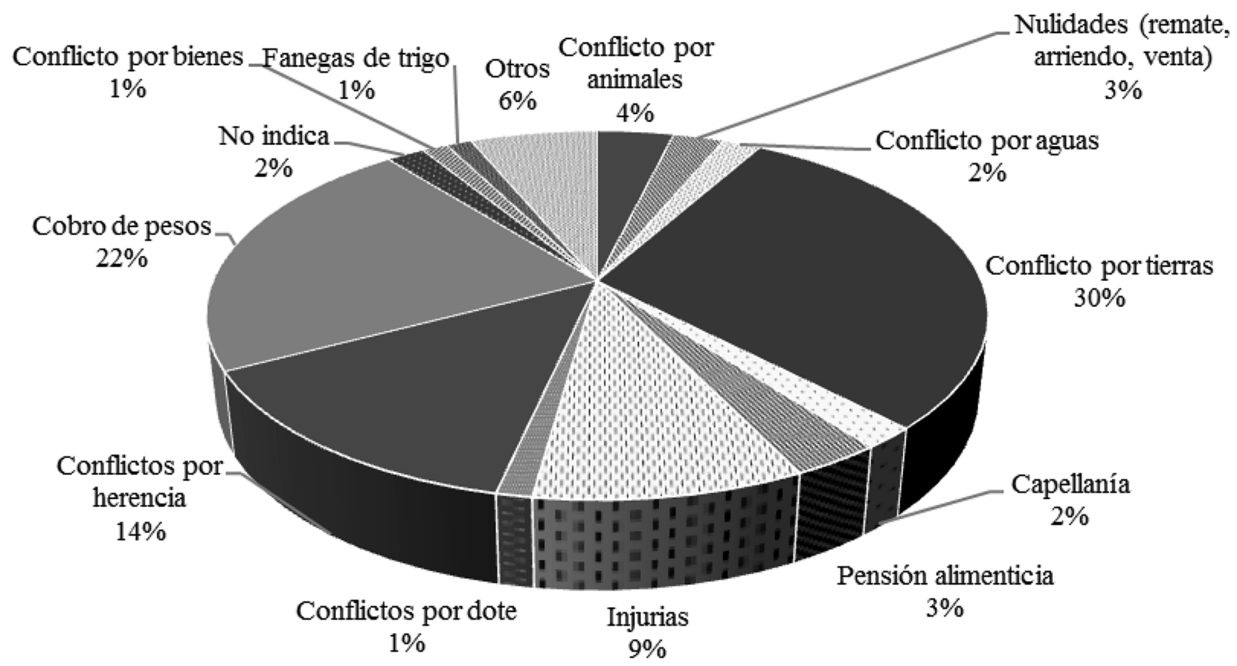

Fuente: Archivo Nacional de la Administración, Fondo Notarios de Rengo vol. 20, 1832-1836.

en que éstas eran firmadas por las partes; lo que no sucedía en Quillota donde este trámite era completa responsabilidad del escribano.

Al igual que en Quillota, los escribanos de Rengo asumirían un papel determinante en la justicia conciliatoria, no sólo registrando el desarrollo de los juicios en las actas, sino también validando esta instancia como mecanismo de resolución de conflictos y participando activamente en ella. En la villa de Rengo, los escribanos que actuaron en la justicia conciliatoria entre los años 1832 y 1836 también participaron como partes involucradas, como jueces compromisarios y también como terceros en discordia. De un total de 159 conciliaciones, el escribano José Calisto González participó en el 69\%, en tanto que José Antonio Latorre en el 11\%, Francisco Zúñiga en el 6\%, Cecilio Quinteros en el 4\% y en el 10\% se desconoce. En la ciudad de Quillota dos escribanos intervinieron en un número similar de juicios de conciliación entre los años 1830 y 1836: José Antonio Venegas participó en el 33\% -de un total de 140 conciliaciones-y José de Torres en el 34\%, en tanto que el 33\% de 


\section{GRÁFICO N $\mathrm{N}^{\circ}$}

\section{Jueces conciliadores en juicios de conciliación de Quillota. 1830-1836. \\ Total de ciento cuarenta conciliaciones.}

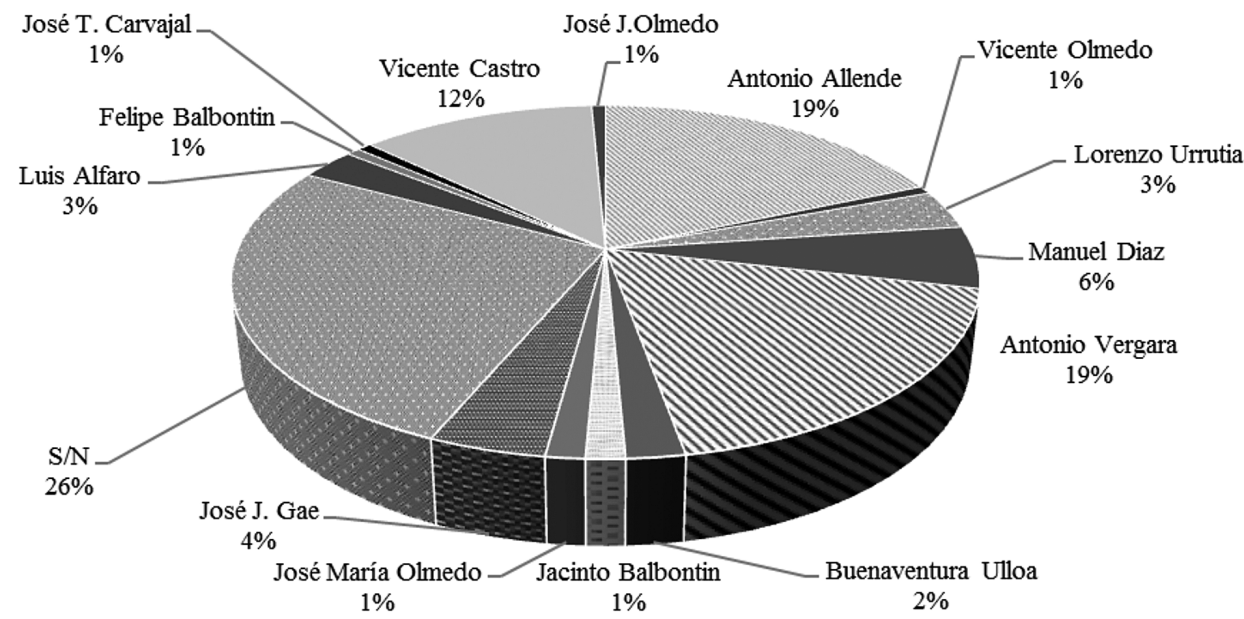

Fuente: Archivo Histórico Nacional, Judicial de Quillota, leg.12, 1834-1836.

Archivo Nacional de la Administración, Fondo Notarios de Quillota, vol. 51, 1830-1836.

las actas de conciliación no individualizaron al escribano ${ }^{45}$. Las identidades de los jueces conciliadores y su participación en la justicia conciliatoria de la ciudad de Quillota fue la que se describe arriba, en el gráfico $n^{\circ} 5$.

Las actas de conciliación de Quillota, con indicación de fecha y de lugar, comenzaban señalando que el demandante concurría ante el juez de conciliación para «querellarse» contra el demandado, que era citado al Juzgado de conciliación «con las esquelas de estilo» ${ }^{46}$. Si el demandado no concurría al juzgado -lo que, como expresa el gráfico $\mathrm{n}^{\circ} 6$ sucedía en el $4 \%$ de los casos de un total de 140 juicios-, ello quedaba registrado en las actas de la siguiente manera: «Y habiendo hecho citar por tres consecutivas veces a D. Mariano Iñigues propietario y administrador de Chilicauquen contestó desentendiéndose

${ }^{45}$ Actas de Conciliación, ANA, Fondo Notarios de Quillota (en adelante FNQ), vol. 51, 1830-1836. Cuaderno de Actas de Conciliación, 1835, Archivo Histórico Nacional, Chile (en adelante AHN), Fondo Judicial de Quillota (en adelante FJQ), legajo 12, 1834-1836.

${ }^{46}$ Actas de Conciliación, 1830, ANA, FNR, vol. 20, fj. 1. 
de la demanda» ${ }^{47}$. Esta constancia era relevante, como prescribía el artículo 18 del Reglamento de Administración de Justicia de 1824, para emitir el certificado que daba cuenta del inicio del trámite de conciliación que permitía luego al demandante concurrir al Juzgado de primera instancia. Asimismo, quien no había comparecido ante el juez de conciliación quedaba condenado al pago de costas si, luego de seguir la instancia en el curso ordinario, «no obtuviere su fallo definitivo» ${ }^{48}$.

Las actas daban cuenta del carácter verbal del procedimiento, incluso en algunos casos consignaban referencias al conflicto entre las partes: «después de varios alegatos que tuvieron sobre la materia queastionada» ${ }^{49}$, «habiéndose subcitado varios artículos, contradicciones y alegatos, sobre la citada escritura, su tenor y demás pormenores» ${ }^{50}$, «a una voz dijeron que no se conciliaban y que querían seguir el Juicio hasta su conclusión», ${ }^{51}$ "y así después de varios alegatos, y conferencias»" ${ }^{52}$, así como "se subsitaron varias diferencias y alegatos, recíprocos $\rangle^{53}$. Estas referencias a discusiones y palabras alteradas entre las partes tenían como escenario el juzgado de conciliación, en el momento del «comparendo», cuando ellas concurrían a la citación del juez y este procedía a escuchar su versión de los hechos ${ }^{54}$. En las disputas entre familiares o en los conflictos por injurias podía ocurrir que las partes expresaran verbalmente su animosidad ante el juez de conciliación, el que muchas veces debía detener el comparendo para evitar mayores problemas. Eso fue lo que sucedió en el juicio entre don Pedro Almeyda y su suegra doña María Antonia Olmos, quien era acusada por su yerno de haberle engañado sobre el origen legítimo de su hija y los consiguientes derechos hereditarios de la misma. El escribano consignó que «se subsitaron varias voces y alegatos de parte a parte» ${ }^{55}$; una frase que también podía encontrarse en las disputas por cobro de pesos, como sucedió

${ }^{47}$ Ibidem, FNQ, vol. 51, fj. 11.

48 Reglamento de Administración de Justicia de 1824, artículo 18 en Anguita, 1912, tomo I: 152 .

49 Actas de Conciliación, 1830, ANA, FNQ, vol. 51, fj. 1.

${ }^{50}$ Ibidem, fj. $27 \mathrm{v}$.

${ }^{51}$ Ibidem, 1831, ANA, FNQ, vol. 51, fj. 56v.

${ }^{52}$ Ibidem, 1832, ANA, FNQ, vol. 51, fj. 64v.

${ }^{53}$ Ibidem, fj. 68.

54 Tanto las actas de Quillota como las de Rengo llaman «comparendo» a la instancia del juicio de conciliación en que las partes, compareciendo en conjunto ante el juez de conciliación, relatan su versión de los hechos.

${ }_{55}$ Actas de Conciliación, 1831, ANA, FNQ, vol. 51, fj. 35. Expresiones similares también se encuentran en un conflicto entre familiares sobre nulidad de una disposición testamentaria (Actas de Conciliación, 1833, ANA, FNQ, vol. 51, fj. 76) y en una disputa por injurias (Actas de Conciliación, 1833, ANA, FNQ, vol. 51, fj. 77v). 
en 1832 entre los herederos de Benedicto Arabena y don Francisco Barba ${ }^{56}$. El escribano podía incluso permitirse consignar «la terquedad de las partes» involucradas en un conflicto por injurias, la que impedía al juez de conciliación propiciar el avenimiento ${ }^{57}$. Sin embargo, en la mayoría de las ocasiones, las partes presentaban sus argumentos de manera pausada y se establecía un diálogo respetuoso entre ellas.

El carácter verbal del procedimiento también se evidenciaba en otras circunstancias. En una ocasión, las actas de conciliación de Quillota recogieron el testimonio de un involucrado que planteó que su extrema timidez le impedía afrontar el juicio. En 1832 don Antonio Arancibia, demandado por partición de bienes, presentó cinco testigos que apoyaban su posición junto a «una especie de representación de fecha veinte del presente y corre en el Espediente a f por que dijo que su corto genio y lo mismo sus palabras no le permitían hacerlo de otra suerte ${ }^{58}$. Como se trataba de un procedimiento verbal que era registrado por el escribano y, por tanto, sometido a su mediación, las actas de conciliación contenían omisiones y censuras tanto de las opiniones del juez como de las enunciadas por las partes. En 1831, José de Torres, escribano público y de conciliación, resumió y omitió parte importante de las reconvenciones que el juez de conciliación realizó ante unos familiares envueltos en un conflicto por injurias, consignando que «les espuso a las partes lo odioso, costoso, y por ultimo lo transedental que son estas [...] por su naturalesa, y que tanto por lo espuesto, como por ser personas bastante cercanas como ser tío y sobrino político, y otras mil consideraciones que no es del caso el espresar.... $\rangle^{59}$.

Luego de escuchar los argumentos de las partes los jueces conciliadores procedían a proponer medios de avenimiento «espontáneos», como señalaba el Reglamento de 1824. Esto significaba que las partes, con ayuda del juez conciliador, debían hallar entre ellas -de manera dialogada y negociada- la mejor forma de resolver el diferendo. Si ambas partes concordaban, sobrevenía un avenimiento total entre ellas, que en Quillota se producía en el $21 \%$ de los juicios de conciliación, de un total de 140, como indica el gráfico $\mathrm{n}^{\circ} 6 .^{60}$ Como se observa en el gráfico $n^{\circ} 6$, en el $10 \%$ de los juicios de conciliación de Quillota el juez conciliador decidió derivar el conflicto a un juicio práctico o recomendó a las partes nombrar jueces compromisarios, árbitros, arbitradores $\mathrm{y}$ amigables componedores, junto a un tercero que mediara en el comparendo

\footnotetext{
56 Actas de Conciliación, 1832, ANA, FNQ, vol. 51, fj. 67v.

57 Actas de Conciliación, 1831, ANA, FNQ, vol. 51, fj. 37v.

58 Actas de Conciliación, 1832, ANA, FNQ, vol. 51, fj. 69v.

59 El subrayado es nuestro. Actas de Conciliación, 1831, ANA, FNQ, vol. 51, fjs. 29 y 29v.

60 Por ejemplo: Cuaderno de Actas de Conciliación, 1835, AHN, FJQ, legajo 12, fj. 39v.
} 


\section{GRÁFICO N ${ }^{\circ} 6$ \\ Porcentaje de providencias en juicios de conciliación de Quillota. 1830-1836 \\ Total de ciento cuarenta conciliaciones.}

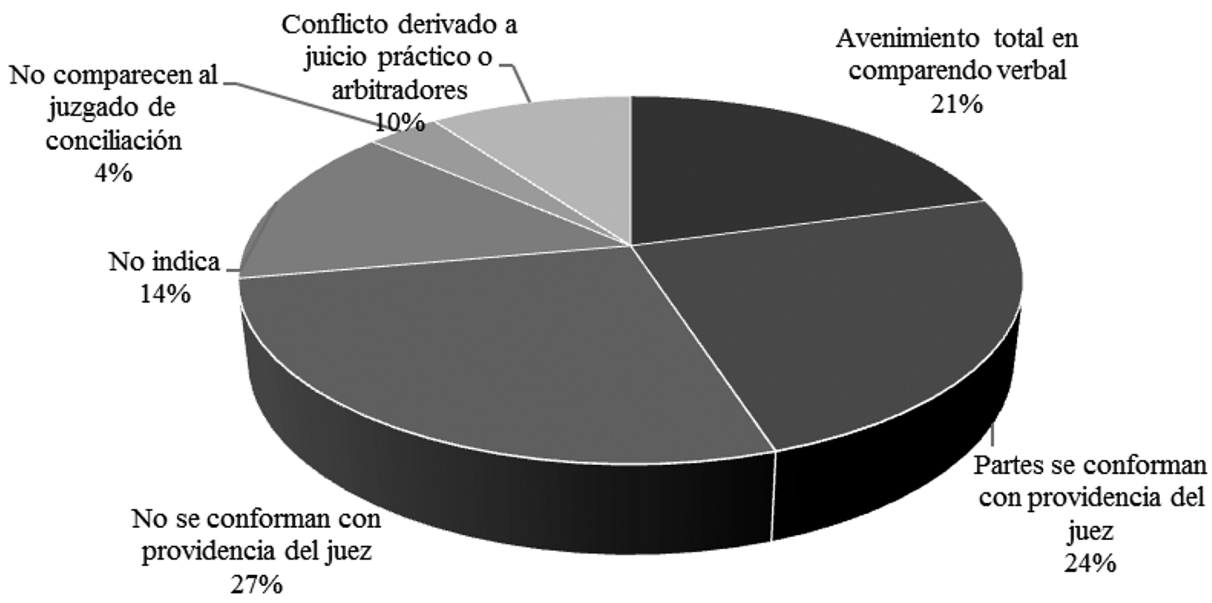

Fuente: Archivo Histórico Nacional, Fondo Judicial de Quillota, leg.12, 1834-1836. Archivo Nacional de la Administración, Fondo Notarios de Quillota, vol. 51, 1830-1836.

verbal. Como indica el título IV del Reglamento de Administración de Justicia de 1824 esto sucedía cuando se disputaban deslindes, cursos de aguas, pertenencias mineras y otras materias que requerían «conocimientos locales i examen del objeto examinado» ${ }^{61}$. En el caso de los juicios de conciliación de Quillota esto ocurrió en conflictos por venta de tierras, cobro de pesos, nulidad testamentaria, cursos de agua, partición de tierras, anulación de cláusula testamentaria, partición de bienes, arriendo de propiedad y pensión alimenticia ${ }^{62}$.

${ }^{61}$ Reglamento de Administración de Justicia de 1824, artículos 38-44 en Anguita, 1912, tomo I: 153-154. Ello también estaba establecido en el título XVI de la Constitución de 1823. Constitución de 1823, artículos 176-179 en Anguita, 1912, tomo I: 137.

${ }^{62}$ Los jueces compromisarios, árbitros, arbitradores, amigables componedores y tercero en discordia eran: Pedro Fernández Macaya, José María Barba, Roque Rodríguez, Francisco Buceta, Pedro de Mena, Vicente Balbontín, José Ignacio Olmedo, José Toppeti, Antonio Allende, José Antonio Moreno, José Jesús Gae, José Agustín Moran, José Torres, Juan José Jorquera, José María Ortiz de Zara, Juan Ignacio Campo, Isidro Blanco, José Joaquín Orrego, Vicente Albares de Araya, Vicente Castro, Joaquín Orrego, Manuel Díaz, Juan Agustín Prado, Francisco de Salamanca y Pedro Vásquez. Actas de Conciliación, 1830, ANA, FNQ, vol. 51, 
En la villa de Rengo, entre 1832 y 1836 , no existe constancia de que la parte demandada no concurriera al juzgado de conciliación al ser citada por el juez, como se observa en el gráfico $\mathrm{n}^{\circ} 7$. Este mismo instrumento nos indica que el porcentaje de avenimiento total entre las partes, luego de desarrollado el comparendo verbal, era mucho menor que en Quillota. La mayor representación de juicios prácticos y derivados a árbitros y arbitradores en Rengo que en Quillota se explica por el importante número de juicios por propiedad de la tierra en Rengo, los que frecuentemente requerían intervenciones de peritos ${ }^{63}$.

Era habitual que al no obtener resultados positivos el juez de conciliación suspendiera el comparendo. Esta situación se planteaba en el 51\% de los casos de Quillota, de un total de 140, como indica el gráfico $\mathrm{n}^{\circ} 6$ al sumar las variables «No se conforman con providencia del juez»y «Partes se conforman con providencia del juez». Luego de citar los artículos $7^{\circ}$ y $8^{\circ}$ del Reglamento de Administración de Justicia de 1824, el juez conciliador suspendía el juicio y tenía ocho días para dictar su «providencia» o resolución sobre el mismo, lo que se registraba en el acta: «Se suscitaron otras varios alegatos por ambas partes; y habiéndoles propuesto el señor juez los medios conciliatorios, no fue posible avenirlos. En este estado mandó suspender el juicio según lo prevenido en el artículo $7^{\circ}$ del Reglamento de Justicia» ${ }^{64}$. En tanto, en las actas de conciliación de la villa de Rengo, no tenemos total certeza sobre el número

fj. 1. Actas de Conciliación, 1832, ANA, FNQ, vol. 51, fj. 64. Actas de Conciliación, 1833, ANA, FNQ, vol. 51, fj. 75v y 81. Actas de Conciliación, 1834, ANA, FNQ, vol. 51, fjs. 96, 97v y 99v. Actas de Conciliación, 1835, ANA, FNQ, vol. 51, fj. 87. Cuaderno de Actas de Conciliación, 1834, AHN, FJQ, legajo 12, fjs. 2, 3, 4v y 6. Cuaderno de Actas de Conciliación, 1834, AHN, FJQ, legajo 12, fjs. 16 y 31.

${ }^{63}$ Las actas de Rengo registran los nombres de los jueces prácticos, tercero en discordia, jueces árbitros, arbitradores y amigables componedores: Feliciano Silva, José Patricio de Latorre, Antonino García, Luis Solís, José Patricio de Latorre, José Manuel Herrera, José Ramón Pizarro, Fermín López, José Miguel Gutiérrez, Alejandro Sepúlveda, Felipe Santiago de Latorre, José María Ramírez, José Ignacio Bustamante, Manuel Ramírez, Ángel Escobar y José Anguita. Actas de Conciliación, 1832, ANA, FNR. vol. 20, fjs. 12, 171, 174. Actas de Conciliación, 1833, ANA, FNR, vol. 20, fjs. 25v, 27v, 31, 35v, 48, 57. Actas de Conciliación, 1834, ANA, FNR, vol. 20, fjs. 63, 78v, 83v, 88v. Actas de Conciliación, 1835, ANA, FNR, vol. 20, fjs. 120v, 122v. Actas de Conciliación, 1836, ANA, FNR, vol. 20, fjs. 126, 128, 132v, $138 \mathrm{v}, 140,152 \mathrm{v}, 154 \mathrm{v}, 159,165 \mathrm{v}, 167$. De $\operatorname{los} 25$ juicios derivados a juicio práctico o a la intervención de jueces árbitros, arbitradores y amigables componedores se aprecia la siguiente distribución porcentual: conflictos por tierras $(44 \%)$, por cobro de pesos $(28 \%)$, por herencia $(16 \%)$, por animales $(4 \%)$, por aguas $(4 \%)$ y otros $(4 \%)$.

${ }^{64}$ Cuaderno de Actas de Conciliación, 1835, AHN, FJQ, legajo 12, fj. 21. También: «Se sucitaron otros varios alegatos que no hacian al caso, por lo que el señor juez le propuso medios conciliatorios que no tuvieron efecto, y fue de parecer...». Cuaderno de Actas de Conciliación, 1836, AHN, FJQ, legajo 12, fj. 45. 


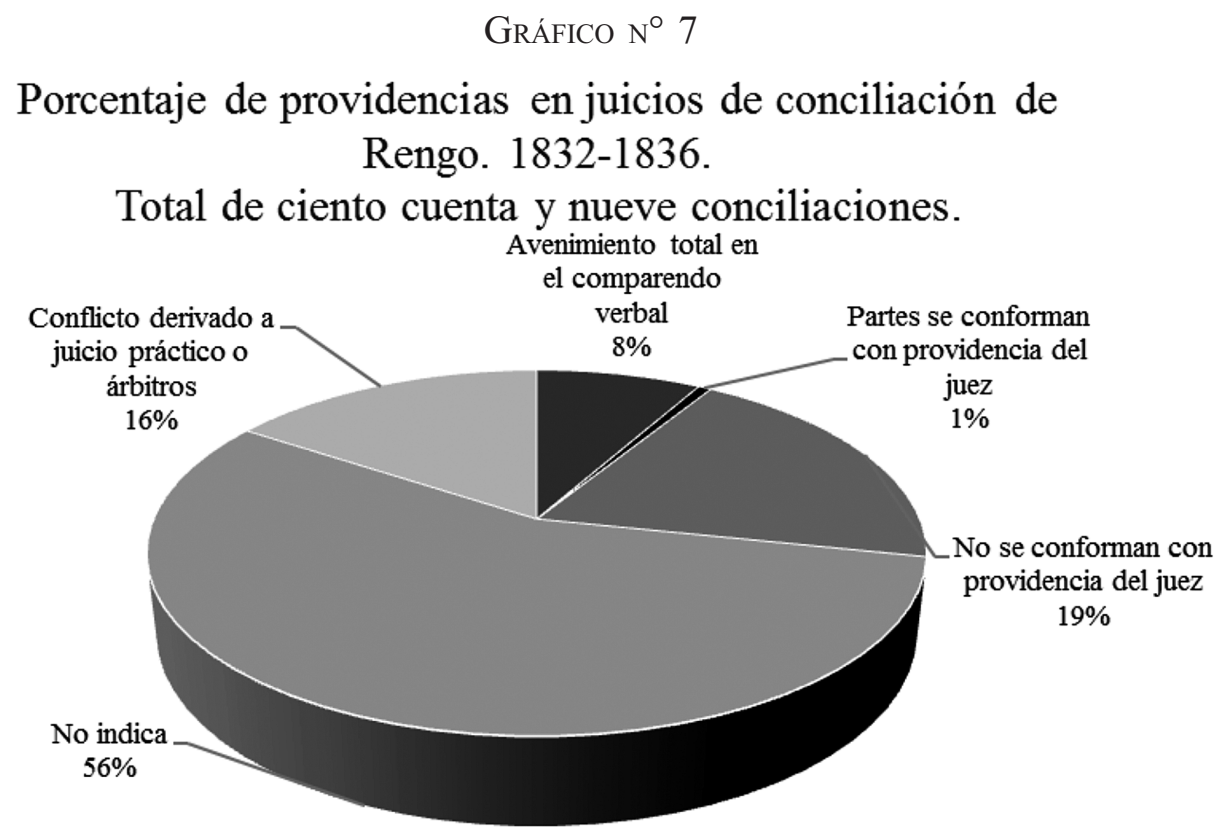

Fuente: Archivo Nacional de la Administración, Fondo Notarios de Rengo vol. 20, 1832-1836.

de juicios de conciliación en los que el juez suspendía el comparendo para dictar su providencia, pues en el 56\% de ellos - de un total de 159 - no se indica con precisión si se produjo o no la resolución del conflicto y a través de qué medio. Sólo podemos establecer que, al menos, en el $20 \%$ de ellos -como se observa en el gráfico $\mathrm{n}^{\circ} 7$ al agregar las variables «No se conforman con providencia del juez»y «Partes se conforman con providencia del juez»- el juez procedió a dictar su providencia.

Como jueces legos, los jueces de conciliación resolvían en conciencia, según su parecer y de acuerdo a la costumbre. Para dictar sus providencias ellos consideraban «los documentos manifestados [y] las esposiciones respectivas de las partes ${ }^{65}$. Este raciocinio se expresaba en las actas de conciliación a través de este tipo de enunciados: «En esta atención y a fin de dar Su Dictamen [...] después de haber meditado sobre todas y cada una en particular de las citadas

${ }^{65}$ Actas de Conciliación, 1830, ANA, FNQ, vol. 51, fj. 7. Estas expresiones registraban leves variaciones: «En esta virtud, visto los documentos que ejecutasen y se han obrado en los autos, y las razones alegadas por las partes, soy de parecer que...». Actas de Conciliación, 1830, ANA, FNQ, vol. 51, fj. 8. 
reciprocas propuestas, el Señor Juez de conciliaciones dio su dictamen y parecer que... $\rangle^{66}$. Muy excepcionalmente las actas incluían referencias a leyes en la formulación de la providencia de conciliación. Sin embargo, es importante destacar que los jueces de conciliación demostraban conocer los artículos del Reglamento de Administración de Justicia de $1824{ }^{67}$. Este estipulaba que el juez conciliador tenía un plazo de ocho días para dictar su providencia, lo que en Quillota se cumplió en el 20\% de los casos -de un total de 140 juicios de conciliación-, en tanto que en el 33\% los jueces excedieron el plazo y en el $47 \%$ de los casos el documento no indicó la fecha ${ }^{68}$.

Las partes envueltas en el juicio de conciliación conocían esta norma y la invocaban cuando ella se infringía, lo que sin duda constituía evidencia de su cultura jurídica. Esto último se comprenderá más cabalmente al analizar el perfil social de los usuarios de la justicia conciliatoria, que realizaremos en el siguiente apartado. Uno de los casos en los que constó el retraso en la determinación de la providencia de conciliación, las partes señalaron no conformarse a ella pues por su atraso «había cesado de derecho su autoridad [la del juez conciliador] para resolver» ${ }^{69}$. En general, la providencia del juez conciliador era notificada por el escribano a las partes involucradas, las que debían indicar si se conformaban o no con ella. Como se observa en el gráfico $\mathrm{n}^{\circ} 6$, en el $24 \%$ de los juicios de conciliación celebrados en Quillota ambas

\footnotetext{
${ }^{66}$ Actas de Conciliación, 1830, ANA, FNQ, vol. 51, fjs. 2v y 3. También: Actas de Conciliación, 1830, ANA, FNQ, vol. 51, fj. 22.

${ }^{67}$ Las leyes citadas en las actas de conciliación de Quillota, además del Reglamento de Administración de Justicia de 1824 eran la ley 9 tit. 14 partida 3; ley 1 tit. 1 libro $5^{\circ}$ de la Recopilación; ley 2 tit. 16 lib. $5^{\circ}$ de la Recopilación; ley 2 tit. 18 libro $5^{\circ}$ de la Recopilación. Cuaderno de Actas de Conciliación, 1834, AHN, FJQ, legajo 12, fj. 5. Actas de Conciliación, 1830, ANA, FNQ, vol. 51, fj. 24v. Actas de Conciliación, 1831, ANA, FNQ, vol. 51, fj. 35. Cuaderno de Actas de Conciliación, 1834, AHN, FJQ, legajo 12, fjs. 10v, 12v. En las actas de Rengo se citaron leyes en 11 de 159 juicios de conciliación. La mayoría referían al Reglamento de Administración de Justicia de 1824, en tanto que las otras eran: leyes 6, 7 y 8, tit. 5 partida 5, «Mayorazgos de Castilla»; ley 14 tit. 7 libro 5 de Castilla; ley 2 tit 16, libro 5 de la Recopilación; ley 1 tit. 1, libro 10 de la Novísima Recopilación; ley 2 tit. 12 partida 5, ley 9 tit. 3 libro 5 de la Recopilación; ley 9 tit. 19 partida 6; ley 28 tit. 19 partida 3. Actas de Conciliación, 1832, ANA, FNR, vol. 20, fj. 15. Actas de Conciliación, 1833, ANA, FNR, vol. 20, fjs. 29-30, 52v-54, 59v. Actas de Conciliación, 1834, ANA, FNR, vol. 20, fj.79. Actas de Conciliación, 18353, ANA, FNR, vol. 20, fjs.43v-45, 48v. Actas de Conciliación, 1836, ANA, FNR, vol. 20, fjs.141v-142v. Sobre la vigencia de la tradición, expresada en el uso de las leyes de las Siete Partidas, ver: Bravo Lira, 1985: 43-105.

${ }^{68}$ Interesa señalar que en el $12 \%$ de los casos el juez dictó su providencia el mismo día del juicio de conciliación. Por su parte, las actas de conciliación de Rengo no indican la fecha de las providencias de los jueces.

${ }^{69}$ Actas de Conciliación, 1832, ANA, FNQ, vol. 51, fj. 59.
} 
partes se conformaron con la providencia del juez, en tanto que en el $27 \%$ de los casos ambas partes -o una de ellas- indicaban que no se conformaban con la resolución, por lo que podían presentar su caso ante un tribunal ordinario. Así, una vez desarrollado todo el proceso de conciliación es posible constatar, para la localidad de Quillota, que el $45 \%$ de los conflictos presentados lograron resolverse en esta instancia, lo que aumentaría a 55\% si sumamos los conflictos que, por su naturaleza, habían sido derivados a juicio práctico.

Una vez más, la distribución porcentual de resolución de los conflictos en los juicios de conciliación de Rengo es difícil de determinar debido a la estructura más abreviada y simplificada de sus actas. Ello planteaba un importante problema metodológico dado que la firma del acta por las partes podía indicar su conformidad con la providencia, implicando un alto porcentaje de aceptación de la resolución del juez, que se presentaría en el $60 \%$ de los 398 involucrados en los juicios de conciliación, como evidencia el gráfico $\mathrm{n}^{\circ} 9^{70}$. Teniendo en cuenta esta ambigüedad y como referencia sujeta a discusión, optamos por elaborar en gráfico $n^{\circ} 7$ considerando sólo los casos en los que se hizo explícita la opinión de las partes, cuya conformidad se expresó en el $1 \%$ de los casos y su disconformidad en el $19 \%$ de un total de 159 juicios de conciliación.

\section{LOS USUARIOS DE LA JUSTICIA CONCILIATORIA}

Como hemos señalado, las partes debían firmar el acta de conciliación. Si no sabían firmar, un representante debía hacerlo ante el escribano encargado del libro de $\operatorname{actas}^{71}$. Conocer la distribución porcentual de las partes que firmaban y de las que no lo hacían por no saber permite aproximarse al perfil social de los usuarios de la justicia conciliatoria. Como indica el gráfico $\mathrm{n}^{\circ}$ 8, de un total de 305 partes involucradas en los juicios de conciliación de Quillota, el $42 \%$ firmó el acta en tanto que el 11\% fue representado por un apoderado firmante del documento. Para el $32 \%$ de los involucrados no aparece su firma y tampoco consta la de un representante. Sólo el 15\% de los involucrados no firmó el acta por no saber hacerlo.

\footnotetext{
${ }^{70}$ Este porcentaje se obtiene de la suma de las variables «firma apoderado»y «firma» del gráfico $\mathrm{n}^{\circ} 9$.

${ }_{71}$ Por ejemplo: «En ocho días del mismo mes le hice saber dicha acta a doña Josefa Billegas, quien en el auto de la notificacion dijo que se conformaba con ella en todas sus partes, y no firmo por no saber de que doy fee= Benegas». Cuaderno de Actas de Conciliación, 1835, AHN, FJQ, legajo 12, fj. 16v.
} 


\section{GRÁFICO N ${ }^{\circ} 8$}

\section{Porcentaje de sujetos que firman en juicios de conciliación. Quillota. 1830-1836. Total de trescientos cinco involucrados.}

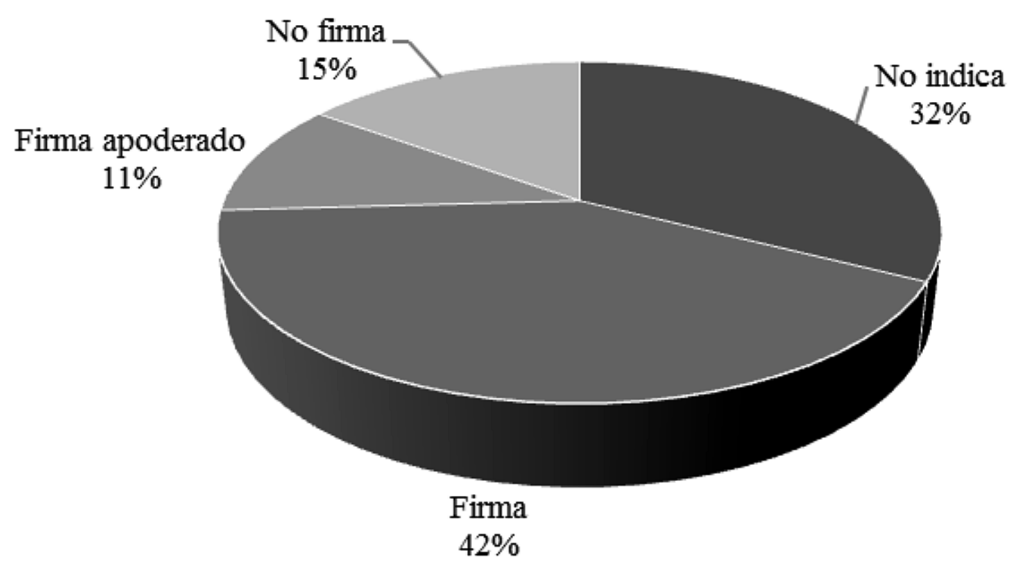

Fuente: Archivo Histórico Nacional, Fondo Judicial de Quillota, leg.12, 1834-1836.

Archivo Nacional de la Administración, Fondo Notarios de Quillota, vol. 51, 1830-1836.

Si separamos a los demandantes de los demandados obtendremos cifras muy similares. Así, en el caso de los demandantes, y considerando un total de 157 individuos, el 41\% firmó el acta de conciliación, el 12\% fue representado por un apoderado, el 14\% no firmó por no saber hacerlo y en el $33 \%$ de los casos no hay referencia a la firma o no del documento. Respecto a los demandados, en el marco de un total de 148 individuos, el $42 \%$ firmó el acta de conciliación, el $10 \%$ fue representado por un apoderado, el $16 \%$ no firmó por no saber hacerlo y en el $32 \%$ de los casos no hay referencia a la signatura del documento.

En el caso de las actas de conciliación de la villa de Rengo, como refiere el gráfico $\mathrm{n}^{\circ} 9$, de un total de 398 involucrados en juicios de conciliación, el 34\% firmó el acta y el 26\% fue representado por un apoderado que firmó el acta por él. Sobre el $37 \%$ no existe referencia a si firmó el documento, en tanto que sólo el 3\% de los involucrados no firmó el acta por no saber hacerlo. Al considerar de manera aislada a los demandantes de los demandados se observan diferencias derivadas de la mayor o menor participación de apoderados, quienes firmaban el acta de conciliación. Así, en el caso de 
GRÁFICO N ${ }^{\circ} 9$

\section{Porcentaje de sujetos que firman en juicios de conciliación. Rengo. 1832-1836.} Total de trescientos noventa y ocho involucrados.

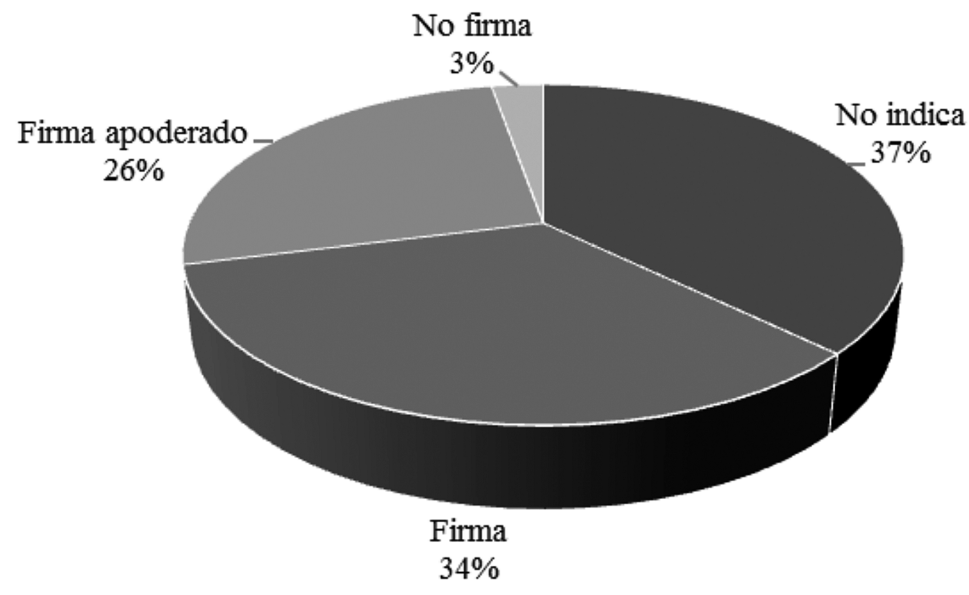

Fuente: Archivo Nacional de la Administración, Fondo Notarios de Rengo vol. 20, 1832-1836.

los demandantes, y considerando un total de 210 individuos, el 26\% firmó el acta de conciliación, el 38\% fue representado por un apoderado, sólo el $2 \%$ no firmó por no saber hacerlo y en el $34 \%$ de los involucrados no hay referencia a la firma o no del documento. Respecto a los demandados, dentro de un total de 188 sujetos, el 43\% firmó el acta de conciliación, el 13\% fue representado por un apoderado, sólo el $4 \%$ no firmó por no saber hacerlo y para el $40 \%$ de los involucrados no hay referencia a la firma del documento.

$\mathrm{Si}$ contrastamos la alta proporción de sujetos que firmaron el acta de conciliación - hayan sido partes involucradas o sus representantes- $\mathrm{y}$, particularmente, el muy bajo porcentaje de individuos que declaraban no saber hacerlo, con las tasas de alfabetización que existían en Chile en ese entonces, constatamos que parte importante de los usuarios de la justicia conciliatoria en Quillota y Rengo pertenecían a los sectores alto y medio-alto ilustrados del país.

Los primeros datos certeros sobre el proceso de alfabetización en Chile corresponden a los arrojados por el censo de 1854. Según este la población total del país alcanzaba 1.439.120 habitantes, de los cuales el $15 \%$ de los 
hombres y el $9 \%$ de mujeres sabían leer y el $13,5 \%$ de los hombres y el $7,8 \%$ de mujeres sabían escribir ${ }^{72}$. Como han planteado Serrano, Ponce de León y Rengifo, la alfabetización dependía del patrón de asentamiento de la población dado que las provincias más urbanizadas presentaban índices más altos que aquellas preponderantemente rurales. Así, en la provincia de Valparaíso -en la que se encontraba la villa de Quillota- la población alfabetizada masculina alcanzaba al 23\% y la femenina al 16\%. En el caso específico de Quillota, el censo de 1854 evidencia que en esta localidad 3.211 hombres sobre $22.919(14.02 \%)$ y 2.811 mujeres sobre $23.473(12.01 \%)$ dominaban la lecto-escritura.

Como Rengo era una villa de importancia menor dentro de la provincia de Colchagua, carecemos de referencias precisas sobre sus tasas de alfabetización durante el periodo estudiado. Sin embargo, contamos con información relativa a las unidades administrativas en las que se ubicaba. Según el censo de 1854 la provincia de Colchagua presentaba una de las menores tasas de alfabetización del país, que en el caso de los hombres llegaba al $11 \%$ y en el de las mujeres al $7 \%{ }^{73}$. Este registro contiene también datos de alfabetización para el Departamento de Caupolicán: 3.530 hombres (12.47\%) sobre un total de 28.329 dominaban la lecto-escritura mientras que 2.767 mujeres $(9.28 \%)$ sobre un total de 29.799 también lo hacían.

Es posible, para el caso de Quillota, complementar los datos de los censos con aquellos contenidos en el Registro Parroquial a través del acta de matrimonio que suele incluir las firmas de los contrayentes. Pese a que los datos son escasos y prácticamente no otorgan suficiente seguridad, se puede señalar lo siguiente: entre 1801 y 1810 el total de matrimonios fue de 645 y el total de novios fue 1290. De estos, las actas con firmas de hombres alcanzaron las 68 y las con firmas de mujeres llegaron sólo a $14^{74}$.

En contraste a las cifras presentadas, que consignan precarias realidades de alfabetización incluso veinte años después de nuestro periodo de investigación, las actas de conciliación de Quillota y de Rengo evidencian que los usuarios de la justicia conciliatoria al menos sabían firmar en el 53\% y en el $60 \%$ de los casos respectivamente. Sin embargo, la cifra más relevante corresponde al muy bajo porcentaje de sujetos que explicitaron no saber firmar, que en el caso de Quillota alcanzó al 15\% y en el de Rengo al 3\%. Estas cifras también pueden interpretarse desde la perspectiva de las diferencias entre los usuarios de la justicia conciliatoria entre Rengo y Quillota. En la primera villa los

\footnotetext{
72 Serrano, Ponce de León y Rengifo, 2012, tomo I: 124.

73 Ibidem: 125-126.

74 Muñoz Quiñones, 1965: 152.
} 
individuos que acudieron a los tribunales de conciliación para resolver sus conflictos pertenecerían a un círculo aún más reducido, de mayor estatus social y con mayor ilustración que en Quillota.

Otra de las conclusiones relevantes obtenidas del análisis cuantitativo de esta documentación ha sido que los usuarios de la justicia conciliatoria acudían a esta instancia en más de una ocasión. De los 55 involucrados que se repiten en las 159 conciliaciones registradas en Rengo, la mayoría participa en dos o en tres juicios de conciliación -como don Santos Román y don Juan Molina- ${ }^{75}$, aunque también se observa a otros -como don Francisco Bisquertt- ${ }^{76}$ participando en once ocasiones y a otros actuando en cuatro $\mathrm{u}$ ocho juicios, como el presbítero don Manuel A. Trincado ${ }^{77}$.

Dentro del grupo de individuos que actuaba frecuentemente en la justicia conciliatoria es posible hallar a muchos de ellos ejerciendo distintos roles: demandante, demandado, representante de una parte, tercero en discordia, juez práctico y escribano. A modo de ejemplo, en el caso de la villa de Rengo, Don Francisco Bisquertt actuaba como defensor de obras pías, como representante y como demandante ${ }^{78}$; don Fermín López actuaba en varias causas como representante y tercero en discordia ${ }^{79}$ y don Alejandro Sepúlveda actuaba como juez práctico, representante, alcalde y también figuraba como juez de primera instancia ${ }^{80}$. Los dos casos más interesantes corresponden a los escribanos don Cecilio Quinteros y don José Antonio Latorre, quienes también asumieron como jueces conciliadores ${ }^{81}$. Asimismo, ambos escribanos actuaron como parte y como representantes de otros sujetos ante el tribunal de conciliación. Sus diversas participaciones y, en particular, sus actuaciones como jueces conciliadores revelan el destacado papel que asumieron los escribanos en las prácticas de la justicia conciliatoria en Chile. Las actas de conciliación de Quillota expresaban una situación simi-

75 Actas de Conciliación, 1832, ANA, FNR, vol. 20, fjs. 15, 16. Actas de Conciliación, 1835, ANA, FNR, vol. 20, fj. 100v. Actas de Conciliación, 1836, ANA, FNR, vol. 20, fj. 151.

${ }^{76}$ Actas de Conciliación, 1833, ANA, FNR, vol. 20, fjs. 19, 32v, 61v. Actas de Conciliación, 1834, ANA, FNR, vol. 20, fjs. 85v. Actas de Conciliación, 1835, ANA, FNR. vol. 20, fjs. 43v, 44v, 122v. Actas de Conciliación, 1836, ANA, FNR, vol. 20, fjs. 66v, 130, 132v, 143v.

77 Actas de Conciliación, 1833, ANA, FNR, vol. 20, fj. 35v. Actas de Conciliación, 1835, ANA, FNR, vol. 20, fj.122v. Actas de Conciliación, 1836, ANA, FNR, vol. 20, fjs. 66v, 67, 143v.

${ }_{78}$ Actas de Conciliación, 1836, ANA, FNR, vol. 20, fj. 130.

${ }^{79}$ Actas de Conciliación, 1833, ANA, FNR, vol. 20, fj. 56. Actas de Conciliación, 1834, ANA, FNR, vol. 20, fj. 78v.

${ }^{80}$ Actas de Conciliación, 1833, ANA, FNR, vol. 20, fj. 50. Actas de Conciliación, 1834, ANA, FNR, vol. 20, fjs. 88v-89v. Actas de Conciliación, 1835, ANA, FNR, vol. 20, fj. 48v.

${ }^{81}$ Actas de Conciliación, 1832, ANA, FNR, vol. 20, fjs. 3, 173. Actas de Conciliación, 1833, ANA, FNR, vol. 20, fjs. 50, 175. Actas de Conciliación, 1836, ANA, FNR, vol. 20, fj. 130. 
lar, constatándose que los individuos involucrados concurrían a la justicia conciliatoria en más de una oportunidad. Los 36 sujetos que integraban el grupo de usuarios tradicionales de la justicia conciliatoria recurrieron a ella en un mínimo de dos -como don Justo Pereda y don Dionisio Gamboa- ${ }^{82}$ y un máximo de nueve oportunidades, como don José María Barba ${ }^{83}$. Estos sujetos asumían distintos roles, pues actuaban como parte, como representantes y como peritos. Asimismo, hallamos a los dos escribanos identificados en la documentación actuando como parte en los juicios de conciliación. Don José Antonio Venegas lo hizo en dos juicios, en tanto que don José de Torres lo hizo en tres oportunidades ${ }^{84}$.

Las múltiples apariciones de don Francisco Bisquertt y don José María Barba en las actas de conciliación de Rengo y Quillota respectivamente ilustran la recurrente participación de individuos de los grupos acomodados en la justicia conciliatoria. Ambos pertenecían a las familias más importantes de las localidades estudiadas. Don Francisco Bisquertt figura en la documentación como subdelegado y defensor de obras pías ${ }^{85}$ y aparece prestando dinero a algunos miembros de la comunidad de Rengo ${ }^{86}$, mientras don José María Barba y don Francisco Barba figuraban en diversas actas de conciliación como jueces compromisarios, representantes de partes en conflictos, albaceas, tutores y curadores de menores ${ }^{87}$. La documentación también permite reconstruir sus

${ }^{82}$ Actas de Conciliación, 1830, ANA, FNQ, vol. 51, fj. 5v. Actas de Conciliación, 1834, ANA, FNQ, vol. 51, fj. f.101v. Cuaderno de Actas de Conciliación, 1836, AHN, FJQ, legajo 12 , fjs. $48 \mathrm{v}, 72$.

${ }_{83}$ Actas de Conciliación, 1830, ANA, FNQ, vol. 51, fjs. 5v, 7v. Actas de Conciliación, 1832, ANA, FNQ. vol. 51, fj. 61v. Actas de Conciliación, 1833, ANA, FNQ, vol. 51, fjs. 66, 74. Cuaderno de Actas de Conciliación, 1834, AHN, FJQ, legajo 12, fj. 4v. Cuaderno de Actas de Conciliación, 1835, AHN, FJQ, legajo 12, fj. 61; 20v. Cuaderno de Actas de Conciliación, 1836, AHN, FJQ, legajo 12, fj. 46v.

${ }^{84}$ Actas de Conciliación, 1830, ANA, FNQ, vol. 51, fj. 76. Actas de Conciliación, 1832, ANA, FNQ. vol. 51, fj. 57. Actas de Conciliación, 1833, ANA, FNQ, vol. 51, fj. 75v. Actas de Conciliación, 1835, ANA, FNQ, vol. 51, fj. 67v. Actas de Conciliación, 1836, ANA, FNQ, vol. 51, fj. $55 \mathrm{v}$.

${ }^{85}$ Actas de Conciliación, 1836, ANA, FNR, vol. 20, fjs. 130, 154.

${ }^{86}$ Actas de Conciliación, 1828, ANA, FNR, vol. 6, fj. 109.

87 Actas de Conciliación, 1824, ANA, FNQ, vol. 46, fj.123v. Actas de Conciliación, 1826, ANA, FNQ, vol. 46, fj. 64v. Actas de Conciliación, 1828, ANA, FNQ, vol. 48, 1828, fj.18v. Actas de Conciliación, 1830, ANA, FNQ, vol. 50, fjs.62v y 142v. Actas de Conciliación, 1831, ANA, FNQ, vol. 50, 1831, fjs.169v y 230. Actas de Conciliación, 1830, ANA, FNQ, vol. 51, fjs.5v, 6v y 7v. Actas de Conciliación, 1833, ANA, FNQ, vol. 51, fj.83v. Cuaderno de Actas de Conciliación, 1834, AHN, FJQ, legajo 12, fjs.1 y 4v. Cuaderno de Actas de Conciliación, 1835, AHN, FJQ, legajo 12, fjs. 20v y 61. Cuaderno de Actas de Conciliación, 1836, AHN, FJQ, legajo 12, fj. 46v. 
redes sociales y ocupaciones, pues ambos aparecían como arrendatarios de fundos agrícolas y urbanos ${ }^{88}$, como prestamistas a miembros de la comunidad y como deudores de vecinos de Santiago ${ }^{89}$.

Asimismo, la escasa referencia a los oficios practicados por los involucrados en los juicios de Quillota -sólo 11 de 305 lo mencionan-corrobora la hipótesis del uso de la justicia conciliatoria preferentemente por sujetos de los sectores alto y medio-alto ${ }^{90}$. Por otra parte, aunque el uso del «don/doña», debido a su masificación desde mediados del siglo XVIII, no expresaba necesariamente un estatus elevado, es importante mencionar que este era utilizado por gran parte de los involucrados en los juicios de conciliación de Quillota y Rengo ${ }^{91}$. En Quillota, de un total de 157 demandantes, 121 utilizó el «don/ doña» lo que correspondía a un $88 \%$ de la muestra, y de un total de 148 demandados, 106 utilizó el «don/doña», lo que equivalía al 72\% ${ }^{92}$. En Rengo, de un total de 210 demandantes, 181 sujetos se presentaron como "don/doña», lo que correspondía a un $86 \%$, y de un total de 188 demandados, 155 sujetos usaron el «don/doña», lo que correspondía al $82 \%$.

La firma del acta era una acción sumamente relevante dentro del trámite de conciliación. Su registro no sólo permitía dar por concluida esta instancia judicial sino que a su vez habilitaba al demandado y al demandante para ocurrir a un tribunal de primera instancia, luego de obtener la papeleta que acreditaba haber sometido el conflicto a un juicio de conciliación. Los escribanos de Quillota comprendieron esta importancia y demostraron gran diligencia en la notificación de las providencias a las partes involucradas. Acudían a sus casas con el libro de actas, incluso en más de una ocasión, hasta hallar al demandante o al demandado. El escribano José de Torres

${ }^{88}$ Actas de Conciliación, 1830, ANA, FNQ, vol. 51, fj.16v. Actas de Conciliación, 1832, ANA,FNQ, vol. 51, fj. 61v. Actas de Conciliación, 1833, ANA, FNQ, vol. 51, fj.74.

89 Actas de Conciliación, 1830, ANA, FNQ, vol. 51, fj. 1v. Actas de Conciliación, 1832, ANA, FNQ, vol. 51, 1832, fj. 66v.

${ }_{90}$ Entre los oficios mencionados encontramos el de «cura», administrador de hacienda, administrador de una viña, comerciante e inspector. Sin embargo, también hallamos registro de un cacique y un peón. Actas de Conciliación, 1830, ANA, FNQ, vol. 51, fjs. 19v, 20. Actas de Conciliación, 1831, ANA, FNQ, vol. 51, fjs. 29, 43v, 47v. Actas de Conciliación, 1832, ANA, FNQ, vol. 51, fj. 64v. Actas de Conciliación, 1833, ANA, FNQ, vol. 51, fj. 76v. Cuaderno de Actas de Conciliación, 1835, AHN, FJQ, legajo 12, fjs. 31, 43. Cuaderno de Actas de Conciliación, 1836, AHN, FJQ, legajo 12, fj. 69v. Para la villa de Rengo contamos con aún más escasas referencias: dos presbíteros y un «defensor de obras pías», Actas de Conciliación, 1833, ANA, FNR, vol. 20, fj. 35v. Actas de Conciliación, 1836, ANA, FNR, vol. 20, fj. 130.

${ }^{91}$ Undurraga, 2012: 169-189.

${ }^{92}$ La diferencia numérica entre demandantes y demandados se explica por el carácter colectivo de algunas demandas, en particular de aquellas que involucraban herederos. 
llegó a ir hasta seis veces a la casa de una demandada hasta encontrarla y certificar su conformidad o inconformidad con la providencia del juez ${ }^{93}$. Una diligencia similar evidenciaron los escribanos de Quillota en la toma de consentimiento y juramento de fidelidad de los jueces compromisarios, árbitros arbitradores y amigables componedores, que se nombraban en algunos juicios de conciliación ${ }^{94}$.

Estos antecedentes demostraban que el papel desempeñado por los escribanos en el funcionamiento y eficacia de la justicia conciliatoria había sido determinante. Ellos actuaban como mediadores entre la justicia conciliatoria y la comunidad, validándola y haciéndola efectiva. En un contexto social configurado por comunidades pequeñas, con vínculos personales estrechos, en los que prácticamente todos se conocían, la función de los escribanos no se limitó a guardar registro de los juicios de conciliación, como establecía el Reglamento de Administración de Justicia de 1824, sino que también se extendió a hacer presente y visible la justicia conciliatoria en los diversos espacios de sociabilidad ${ }^{95}$. Así, por ejemplo, no sólo fue posible observar a los escribanos visitando sistemáticamente los domicilios de las partes, sino también acercándose a los demandantes o demandados en la plaza, en la calle o en el mercado para hacerles presente el curso del juicio de conciliación en el que se hallaban implicados. En 1831, el escribano José de Torres agregó en el acta de conciliación del juicio entre José Cortés y Santos Aguayo que luego de notificar en cuatro oportunidades a Cortés sobre la providencia del juez conciliador, y una vez al padre de este en su domicilio, «ocho días después encontrándolo en la plaza mayor le hice presente la orden del Sor Juez con que le había a apercibir: me respondió que habiendo y a la cuenta y razón, de todo lo acaecido y resuelto con el juzgado de conciliación, a su patrón D. Roberto Marfala, no tenía él que ver ni haber en el asunto: y orientado por mi el Sor Juez de todos estos pormenores, mandó los pusiese por diligencia para su constancia ${ }^{96}$.

93 «Certifico en quanto puedo y ha lugar en derecho, como habiendo ido a casa de la Sra. Da María Antonia Olmos seis consequtibas veces con el objeto de hacerle saber el parecer de la acta de consiliación que antecede, solo hoy de la fha la he encontrado, pues dos veces me dijeron en su casa estar ausente, otras dos he encontrado las puertas cerradas, otras se me dijo estar durmiendo la siesta, y finalmente hoy como quedo espuesto que he conseguido encontrarla en la propia casa en la hora de comer, procedí inmediatamente a notificarle dha acta», Actas de Conciliación, 1831, ANA, FNQ, vol. 51, fj. 36v.

${ }^{94}$ Actas de Conciliación, 1830, ANA, FNQ, vol. 51, fjs. 1-1v.

95 Sobre las formas de sociabilidad en las aldeas y villas de Chile central véase Undurraga, 2005: 17-35. Salinas Meza, 1998: 1-19; 2005: 11-47.

${ }^{96}$ Actas de Conciliación, 1831, ANA, FNQ, vol. 51, fjs. 38 y 38v. 


\section{CONCLUSIONES}

A lo largo de estas páginas hemos reconstruido las prácticas en torno a la administración de la justicia conciliatoria y el perfil social de sus usuarios en dos localidades de Chile central, luego de la implementación de la conciliación como trámite previo a la presentación de demanda judicial ante los tribunales ordinarios por el Reglamento de Administración de Justicia de 1824. Las 299 actas de conciliación de la villa de Rengo y de la ciudad de Quillota sirvieron como laboratorio de observación para el estudio de los tipos de conflicto, su frecuencia, las formas de avenimiento y de providencias a las que se sometieron, así como para analizar el perfil social de sus usuarios y de los funcionarios involucrados y responsables del desarrollo de estos juicios.

Las actas permitieron observar las interacciones entre sociedad y administración de justicia a una escala micro, constatando que la justicia conciliatoria fue usada como instancia de resolución de los conflictos preferentemente por los sectores alto y medio-alto ilustrado de las comunidades locales. Su activa participación en su funcionamiento, a través de sus actuaciones como jueces de conciliación, jueces compromisarios, árbitros, arbitradores, amigables componedores, peritos y escribanos comprobó el carácter activo de la sociedad en la legitimación de la legalidad y la institucionalidad estatal.

Estos hallazgos demostraron que la justicia conciliatoria no consistía en la simple «apropiación» de la técnica del arbitraje por el Estado, como había propuesto la historia del derecho. El «imaginario estatalista» objetado por António Manuel Hespanha -y que supone la centralización del poder, la dicotomía entre Estado y sociedad, así como la existencia formas de vida pública escindidas de los ámbitos domésticos- se muestra insuficiente para explicar el funcionamiento de la justicia conciliatoria ${ }^{97}$. En los casos estudiados, la evidencia documental evidenciaba el peso que tenía la sociedad -en este caso, un sector de las comunidades locales- en la transformación de la justicia en los inicios de la república. En efecto, la alta comparecencia de los demandados a las citaciones de los juzgados de conciliación, junto a la recurrente, activa y diversa participación de un grupo circunscrito de individuos en los juicios desarrollados en las dos localidades, señalaba la relevancia de estos grupos en la validación de las transformaciones institucionales.

La aceptación social de esta instancia también pudo comprobarse, al menos para la ciudad de Quillota, a través de la evaluación de la efectividad de las actuaciones del juez conciliador como mediador de los conflictos, los que en el $45 \%$ de los casos se resolvieron al interior de su juzgado. Investigaciones

${ }^{97}$ Hespanha, 1989; 2002. 
posteriores deberán comprobar esta interrogante para otras localidades de Chile central, ante las dificultades metodológicas que evidenciaron las actas de conciliación de la villa de Rengo para abordarla de manera certera. Por último, este artículo ha mostrado el papel relevante que asumieron los escribanos como agentes de la justicia conciliatoria, no sólo registrando su desarrollo en las actas, sino también validándola como instancia de resolución de conflictos y participando activamente en ella. Su papel de mediadores entre la justicia conciliatoria y la comunidad se hizo evidente de múltiples maneras, tales como, su diligencia en el cumplimiento de los trámites que estaban bajo su responsabilidad, su actuación como jueces conciliadores y su interés en hacer presente y visible la justicia conciliatoria en los diversos espacios de sociabilidad de las villas y ciudades. En un contexto social caracterizado por comunidades pequeñas, con vínculos personales estrechos, el Estado continuaba apoyándose en figuras tradicionales para consolidar su presencia en el territorio.

\section{BiBLIOGRAFÍA}

Agüero, Alejandro, Castigar y perdonar cuando conviene a la república. La justicia penal de Córdoba del Tucumán, siglos XVII y XVIII, Madrid, Centro de Estudios Políticos y Constitucionales, 2008.

Anguita, Ricardo, Leyes promulgadas en Chile desde 1810 hasta el $1^{\circ}$ de junio de 1912, Santiago de Chile, 1912, tomo I.

Barreneche, Osvaldo, "¿Lega o letrada? Discusiones sobre la participación ciudadana en la justicia de la ciudad de Buenos Aires durante las primeras décadas de independencia y experiencia republican", Juan Manuel Palacio y Magdalena Candioti (comp.), Justicia, política y derechos en América Latina, Buenos Aires, Prometeo, 2007: 181-202.

Bauer, Arnold J., La sociedad rural chilena: desde la conquista española a nuestros días, Santiago de Chile, Andrés Bello, 1994.

Bilot, Pauline, "Construyendo un esquema de la administración de justicia: fuentes, método y resultados. Chile, siglo XIX", Revista Historia y Justicia, 1 (Santiago de Chile, 2013): 1-27. revistahistoriayjusticia.org.

Bilot, Pauline y Whipple, Pablo, "Los desafíos de La justicia republicana. Profesionalización e independencia de la judicatura en Chile y Perú durante el siglo XIX", Antonini De Francesco, Luigi Mascilli Migliorini y Raffaele Nocera (coords.) Entre Mediterráneo y Atlántico. Circulaciones, conexiones y miradas. 1756-1867, Santiago de Chile, FCE, 2014: 477-500. 
Brahm, Enrique, Mariano Egaña: derecho y política en la fundación de la república conservadora, Santiago de Chile, Centro de Estudios Bicentenario, 2007.

Brangier, Víctor, "Relaciones lego-letrado en la Historia de la Justicia: Argentina y Chile, siglos XVIII y XIX", SudHistoria, 5 (Santiago de Chile, julio-diciembre 2012). http://www.sudhistoria.cl/?page_id=2107.

Bravo Lira, Bernardino, "Vigencia de las Partidas en Chile", Revista de Estudios Histórico-Jurídicos, X (Valparaíso, 1985): 43-105.

Castillo, Vasco, "El pensamiento republicano en Chile: el caso de Juan Egaña", Revista de Ciencia Política, 21/1 (Santiago de Chile, 2001): 25-40.

Castillo, Vasco, La creación de la República. La filosofía pública en Chile 1810-1830, Santiago de Chile, LOM Ediciones, 2009.

Clavero, Bartolomé; Portillo, José María y Lorente, Marta, Pueblos, Nación, Constitución (en torno a 1812), Vitoria, Ikusager Ediciones, 2004.

Di Gresia, Leandro A., "Una aproximación al estudio de la cultura judicial de la población rural del sur bonaerense. Tres Arroyos, segunda mitad del siglo XIX", Darío Barriera (coord.), La justicia y las formas de la autoridad. Organización política y justicias locales en territorios de frontera. El Río de la Plata, Córdoba, Cuyo y Tucumán, siglos XVIII y XIX, Rosario, ISHIR, CONICET, Red Columnaria, 2010: 155-191.

Días Blanco, José Manuel, "Política urbana de Tomás Marín de Poveda en Chile: Las fundaciones de Rengo y Talca en su contexto", Francisco Andújar Castillo y Domingo Giménez Carrillo (eds.), Riqueza, poder y nobleza: los Marín de Poveda, una historia familiar de siglo XVII vista desde España y Chile, Almería, Ed. Universidad de Almería, 2011: 163-176.

Dougnac, Antonio, "La conciliación previa a la entrada en juicio en el Derecho patrio chileno (1823-1855)", Revista de Estudios Histórico-Jurídicos, XVIII (Valparaíso, 1996): 111-168.

Fradkin, Raúl (comp.), "La ley es tela de araña". Ley, justicia y sociedad rural en Buenos Aires, 1780-1830, Buenos Aires, Prometeo, 2009a.

Fradkin, Raúl, “¿Misión imposible? La fugaz experiencia de los jueces letrados de Primera Instancia en la campaña de Buenos Aires (1822-1824)", Darío Barriera (comp.), Justicias y fronteras. Estudios sobre historia de la justicia en el Río de la Plata. Siglos XVI-XIX, Murcia, Editum, 2009b: 143-164.

Galante, Mirian; Irurozqui, Marta y Argeri, María A., La razón de la fuerza y el fomento del derecho. Conflictos jurisdiccionales, ciudadanía y mediación estatal (Tlaxcala, Bolivia, Norpatagonia, siglo XIX), Madrid, CSIC, 2011.

Garavaglia, Juan Carlos, "La justicia rural en Buenos Aires durante la primera mitad del siglo XIX (estructuras, funciones y poderes locales)", Juan Carlos Garavaglia, 
Poder, conflictos y relaciones sociales. El Río de la Plata, XVIII-XIX, Rosario, Ediciones Homo Sapiens, 1999: 89-121.

Garriga, Carlos y Lorente, Marta, Cádiz 1812. La constitución jurisdiccional, Madrid, Centro de Estudios Políticos y Constitucionales, 2007.

Garriga, Carlos, "Continuidad y cambio del orden jurídico", Carlos Garriga (ed.), Historia y Constitución. Trayectos del constitucionalismo hispano, México, CIDE, Instituto Mora, El Colegio de Michoacán, 2010.

Gelman, Jorge, "Crisis y reconstrucción del orden en la campaña de Buenos Aires. Estado y sociedad en la primera mitad del siglo XIC", Boletín del Instituto de Historia Americana y Argentina "Dr. Emilio Ravignani", 21 (Buenos Aires, primer semestre 2000): 7-32.

Hespanha, António Manuel, Visperas del Leviatán. Instituciones y poder político (Portugal, siglo XVII), Madrid, Taurus Humanidades, 1989.

Hespanha, António Manuel, Cultura jurídica europea. Síntesis de un milenio, Madrid, Tecnos, 2002.

Irurozqui, Marta y Galante, Mirian (eds.), Sangre de Ley. Justicia y violencia en la institucionalización del Estado en América Latina, siglo XIX, Madrid, Ediciones Polifemo, 2011.

Jaksic, Iván, Andrés Bello: la pasión por el orden, Santiago de Chile, Universitaria, $2010,3^{\mathrm{a}}$ ed.

Jaksic, Iván, Rebeldes académicos: la filosofía chilena desde la Independencia hasta 1989, Santiago de Chile, Eds. Universidad Diego Portales, 2013.

Keller, Carlos, "Los orígenes de Quillota", Boletín de la Academia Chilena de la Historia, 61 (Santiago de Chile, 1960): 97-130.

Lorente, Marta (coord.), De justicia de jueces a justicia de leyes: hacia la España de 1870, Madrid, Consejo General del Poder Judicial, 2007.

Lorente, Marta, "Algunas reflexiones sobre las Cortes de Cádiz y la contribución de los delegados hispanoamericanos", Antonini De Francesco, Luigi Mascilli Migliorini y Raffaele Nocera (coords.), Entre Mediterráneo y Atlántico. Circulaciones, conexiones y miradas. 1756-1867, Santiago de Chile, FCE, 2014: 279-298.

Morelli, Federica, "Pueblos, alcaldes y municipios: la justicia local en el mundo hispánico entre Antiguo Régimen y Liberalismo", Historia Crítica, 36 (Bogotá, julio-diciembre 2008): 36-57.

Muñoz Quiñones, Norma, "Estudio de los libros parroquiales del Curato de Quillota. 1801-1810", Memoria de Prueba para optar al grado de Licenciada y al título de Profesora de Historia, Geografía y Ciencias Sociales, Escuela de Historia y Geografía, Facultad de Filosofía y Educación, Universidad Católica de Valparaíso, 1965. 
Ossa, Juan Luis, "De Cádiz a la América del Sur: El viaje de una ilusión constitucional", Antonini De Francesco, Luigi Mascilli Migliorini y Raffaele Nocera (coords.), Entre Mediterráneo y Atlántico. Circulaciones, conexiones y miradas. 1756-1867, Santiago de Chile, FCE, 2014: 255-278.

Ossandón, Carlos y Ruiz, Carlos (coords.), Andrés Bello. Filosofía pública y política de la letra, Santiago de Chile, FCE, 2013.

Peralta, Víctor, La independencia y la cultura política peruana (1808-1821), Lima, Fundación M. J. Bustamante de la Fuente, IEP, 2010.

Pérez Rosales, Vicente, Ensayo sobre Chile, Santiago de Chile, Cámara Chilena de la Construcción, Pontificia Universidad Católica de Chile, DIBAM, 2010.

Sala i Vila, Nuria, "Justicia conciliatoria durante el liberalismo hispano en el Perú: el caso de Huamanga", Anuario de Estudios Americanos, 69/2 (Sevilla, juliodiciembre 2012): 423-450.

Salazar, Gabriel y Pinto, Julio, Historia contemporánea de Chile I. Estado, legitimidad y ciudadanía, Santiago de Chile, LOM, 1999.

Salinas Meza, René, "Espacio doméstico, solidaridades y redes de sociabilidad aldeana en Chile tradicional, 1750-1880", Contribuciones Científicas y Tecnológicas, 118 (Santiago de Chile, julio 1998): 1-19.

Salinas Meza, René, "Población, habitación e intimidad en el Chile tradicional", Rafael Sagredo y Cristián Gazmuri (dir.), Historia de la vida privada en Chile. Tomo 1: El Chile tradicional: De la Conquista a 1840, Santiago de Chile, Taurus, 2005: 11-47.

Sanjurjo, Inés Elena, "Justicia de paz y cultura jurídica en el largo siglo XIX en Mendoza (Argentina). El caso del departamento de San Rafael en el sur provincial", Nuevo Mundo Mundos Nuevos [En línea], Debates (Paris, marzo 2010) URL: http://nuevomundo.revues.org/59257.

Serrano, Sol; Ponce de León, Macarena y Rengifo, Francisca, Historia de la Educación en Chile (1810-2010), Tomo I Aprender a leer y escribir (1810-1880), Santiago de Chile, Taurus, 2012.

Undurraga, Verónica, "El honor no es más que la buena opinión: aproximación al honor a partir de la categoría de lo público en el Chile de 1792 a 1822", Bicentenario. Revista de Historia de Chile y América, 4/2 (Santiago de Chile, 2005): 17-35.

Undurraga, Verónica, Los rostros del honor. Normas culturales y estrategias de promoción social en Chile colonial, siglo XVIII, Santiago de Chile, Editorial Universitaria/Centro de Investigaciones Diego Barros Arana/DIBAM, 2012.

Undurraga, Verónica y Gaune, Rafael (eds.), Formas de control y disciplinamiento. Chile, América y Europa, siglos XVI-XIX, Santiago de Chile, Uqbar Editores, Instituto Riva-Agüero de la Pontificia Universidad Católica del Perú, Fondo del Libro, 2014. 
Undurraga, Verónica, "Negociando el orden: comunidades locales y prácticas de conciliación en Chile, 1765-1821", Yéssica González (ed.), Diálogos de Historia. Miradas y alcances de la investigación en Chile con enfoque regional, Temuco, Ediciones Universidad de la Frontera, 2015: 41-61.

Valenzuela Solís de Oviedo, Carlos, Historia de Colchagua, Santiago de Chile, Ed. Andújar, 1997.

Valenzuela, Sergio, "Los tribunales de justicia en tiempos de O'Higgins", Revista Chilena de Historia y Geografia, 149 (Santiago de Chile, 1981): 81-84.

Yangilevich, Melina, “Crónicas de conflicto y desilusión. Prefecturas de campaña, juzgados de paz y comisarías en Buenos Aires (1857-1859)”, Darío Barriera (coord.), La justicia y las formas de la autoridad. Organización política y justicias locales en territorios de frontera. El Río de la Plata, Córdoba, Cuyo y Tucumán, siglos XVIII y XIX, Rosario, ISHIR CONICET, Red Columnaria, 2010: 129-153.

Yangilevich, Melina, "La justicia de paz en la construcción estatal al sur del río Salado (Buenos Aires, $1^{\mathrm{a}}$ mitad del siglo XIX)", Carolina A. Piazzi (coord.), Modos de hacer justicia. Agentes, normas y prácticas: Buenos Aires, Tucumán, Santa Fe durante el siglo XIX, Rosario, Prohistoria ediciones, 2011: 75-92.

Fecha de recepción: 25 de febrero de 2015.

Fecha de aceptación: 24 de agosto de 2015.

\section{Conciliatory Justice Practices and their Social Dimensions. Chile, $1830-1836$}

This paper analyses the conciliatory justice practices and the social profiles of its users in the villages and cities of Central Chile, after the implementation of conciliation as a formality prior to the presentation of a lawsuit before the courts of record from 1824 to 1836 . The 299 conciliatory trials studied suggest that conciliatory justice was a conflict resolution mechanism used mainly by the educated upper and middle-upper classes of the local communities, who were precisely the ones who allowed it to operate by carrying out various administrative functions. The community's active participation-or rather that of said class of the local community-was a determining factor in the validation of this "new" recourse for conflict resolution, noting society's active role in legitimizing State institutions and legality.

KEY words: conciliatory justice; conflict resolution; Central Chile; XIX century. 